\title{
Especialización olivarera, cambios institucionales \\ y desigualdad agraria \\ en la Alta Campiña \\ de Córdoba (siglos XVIII-XX)
}

\author{
ANTONIO LÓPEZ ESTUDILLO
}

PALABRAS CLAVE: desigualdad, renta de la tierra, obreros agrícolas, especialización olivarera.

\author{
CÓDIGOS JEL: N33, Q15, J43, I14.
}

l presente escrito indaga desde varias perspectivas en la evolución de la desi-
gualdad desde fines del Antiguo Régimen en un pueblo de la Campiña Bética.
La investigación parte principalmente de fuentes fiscales, apoyadas cuando procede por cuentas de patrimonios, información registral, del servicio agronómico, etc. Estudia primero la transformación del espacio rural y de la producción agrícola local. Se adentra después en la evolución de la distribución de la propiedad, del excedente agrario y de la renta agraria en general. Por último, se interroga por los efectos que ejercieron sobre la evolución de la desigualdad, tanto las transformaciones sociales e institucionales iniciadas con la crisis del Antiguo Régimen como los procesos de intensificación y especialización olivarera y vitícola que en Aguilar y poblaciones vecinas se desarrollaron con amplia anticipación respecto de otras áreas de Córdoba. 


\section{Olive oil production, institutional changes and agricultural inequality in rural central Cordoba province from the eighteenth to the twentieth century}

\section{KEYWORDS: inequality, land rent, agricultural workers, special- ization in oil production.}

\section{JEL CODES: N33, Q15, J43, I14.}

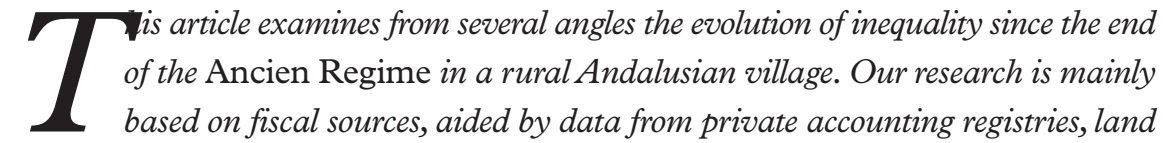
registry documents, texts from agrarian engineers, etc. The transformation of rural spaces and of local agricultural production is discussed first. Second, the evolution of property distribution, agricultural surplus and income are addressed. Last of all, this study explains the inequality effects derived from both socio-institutional transformations begun during the crisis of the Ancien Regime and specialization in wine or olive oil production -combined with intensification in other types of production processes- that took place in Aguilar and the surrounding area much earlier than in the rest of Cordoba Province. 


\section{INTRODUCCIÓN}

El presente artículo estudia la evolución de las desigualdades en uno de los grandes pueblos de la Campiña Bética, Aguilar de la Frontera ${ }^{1}$. La naturaleza de sus transformaciones agrarias incita a contrastar dos propuestas teóricas sobre la desigualdad. La especialización olivarera y el control de la viña local por propietarios acomodados invita a examinar la propuesta de Williamson (2012a. 2012b) de una línea de causación entre especialización, dotación relativa de recursos, remuneración de los factores y desigualdad. Según dicho autor, la concentración de la propiedad y decreciente dotación de tierra por trabajador contribuyó largo tiempo al aumento de la desigualdad, pero esa relación se rompió con los avances del comercio internacional. La inserción en la economía internacional propiciaría en cada área el uso intensivo del factor más abundante, elevando su apreciación relativa, lo que reduciría la desigualdad (renta de la tierra/jornal) donde la tierra constituía el factor escaso, como en Aguilar y el conjunto de Europa occidental. En segundo lugar, la especialización local precisó inversiones en plantaciones y en molinos o lagares en muchas fincas medias y grandes. Una acumulación de capital que, dado que su tasa de remuneración superó regularmente la del crecimiento del producto (Piketty, 2014: 385-396), pudo aportar otro vector favorable al aumento de la desigualdad. La pertinencia de ambas ideas será considerada, pero sin utilizar la historia como banco de pruebas para validar modelos teóricos simples, sino haciendo un empleo moderado y ecléctico de las teorías al servicio del análisis histórico, pues asumimos una causalidad múltiple y cambiante en el tiempo ${ }^{2}$.

La historiografía hispana asume de antiguo esa causalidad múltiple. La consolidación de modelos sociales agrarios, incluso divergentes, en el noroeste, levante y centro-sur peninsular se ha relacionado con las características físicas y las socioinstitucionales de cada área a fines del Antiguo Régimen (Saavedra, 2001), subrayándose también las repercusiones dispares de una revolución liberal que implicó transformaciones substanciales ${ }^{3}$. En Andalucía creció notablemente el número de pequeños propietarios de tierra a partir de la Revolución liberal, y el latifundismo retrocedió modestamente hasta la Segunda República. Un proceso que fue calificado de propietarización limitada, por su alcance muy inferior al de otras áreas de Europa y la polarización que perduró en el reparto de la tie-

1. Incluí informaciones aquí omitidas en un trabajo preliminar (LóPEZ EsTUdILLO, 2011).

2. Críticas recientes a la monocausalidad atemporal en EICHENGREEN (2016) y BRADFORD DELONG (2016).

3. Asumo la agenda crítica de Calatayud, Millán y Romeo (2009) frente a interpretaciones heredadas de la revolución. Son precisas más indagaciones sobre el grado de éxito con que las clases y proyectos sociales que pugnaban consiguieron incorporar elementos de sus respectivas agendas a escala local, preferentemente en etapas de guerra y cambio institucional. 
rra (Grupo de Estudios Agrarios, 2002). Aunque conviene recordar que esa generalización incluye comarcas con trayectorias dispares y aborda solo una de las dimensiones de la desigualdad aquí estudiadas.

Monografías recientes sobre la desigualdad agraria han incorporado enfoques renovadores. Unas han evaluado las transformaciones agrarias desde los flujos de energía o materiales, incorporando explicaciones socioecológicas a la crisis finisecular, las motivaciones de cada colectivo y sus límites ${ }^{4}$. Otras han focalizado su atención en las dinámicas y estrategias familiares ${ }^{5}$. Alguna más ha contrastado las desigualdades en distintos pueblos, jerarquizando a sus propietarios -o cultivadores- de acuerdo con los múltiplos del salario agrario anual masculino a que equivalía el producto de sus tierras ${ }^{6}$.

\section{FIGURA 1}

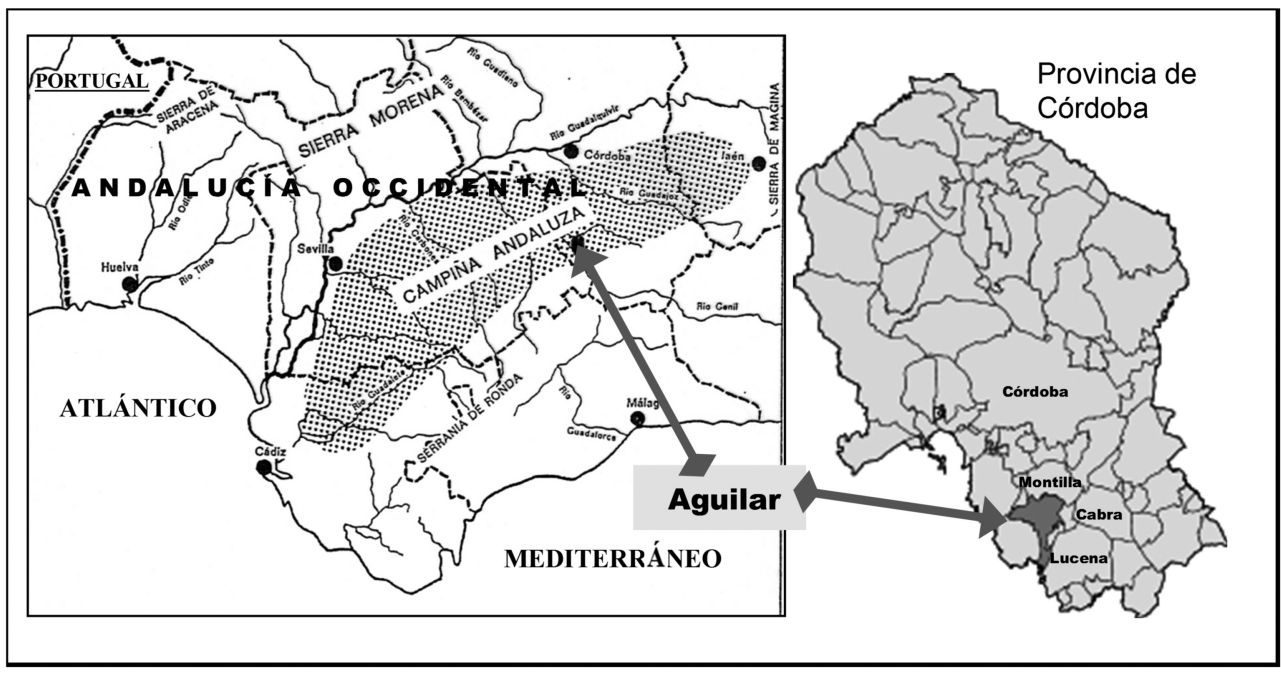

Fuentes: Martínez Alier (1968) e Instituto de Estadística y Cartografía de Andalucía, http://www.juntadeandalucia.es/institutodeestadisticaycartografia/sima/provincia.htm?prov $=14$

El presente escrito se beneficia de sus reflexiones, pero privilegia otros objetivos y adopta una metodología acorde. Pretende estudiar la evolución de tres dimensiones diferentes de la desigualdad agraria y, para ello, recurre a indicadores que, manteniendo su homo-

4. GonzÁlez de Molina et al. (2011); GonzÁlez de Molina, Infante y Herrera (2014); InFANTE (2012); GaRRABOU y TELlo (2004).

5. Un amplio balance historiográfico en GARCía GonZÁLEZ (2016).

6. Garrabou et al. (2014), en el Cuadro 7 emplearé un indicador emparentado con esta jerarquización. 
geneidad, permitan multiplicar los cortes temporales para afinar en la cronología y también ampliar el arco temporal de otros estudios. Esas dimensiones de la desigualdad, interrelacionadas pero alternativas, observaron trayectorias temporales dispares que obligarán a buscar motivaciones específicas.

El ámbito de este estudio, el municipio de Aguilar, formó parte de una jurisdicción de señorío junto a Puente Genil, Monturque, Montalbán y Montilla. Como en otros pueblos del sur de Córdoba, antigua tierra de frontera, una nobleza jurisdiccional perceptora de diezmos propició estrategias poblacionistas de antiguo. Pero si ello redujo la fuerza del frente antirroturador (Llopis, 2004: 30-32) no multiplicó las oportunidades de los pobres a fines del Antiguo Régimen, pues la reserva de tierras roturables era ya muy reducida y la densidad poblacional, elevada desde fines del siglo XVI, experimentó un importante impulso antes de la Revolución liberal ${ }^{7}$.Ya en el siglo XvIII sus principales alternativas fueron la progresión de olivos y viñas, y la intensificación en los herbáceos de secano. Una precoz especialización olivarera, la mejor de las granjerías de la época (Zambrana, 2000: 18), que aupó a Aguilar a una posición destacada en la agricultura peninsular. El cupo de Aguilar por contribución territorial era el 26 mayor de toda España en 1859 y multiplicaba por 2,3 la media española por habitante y por 4,7 la media por kilómetro cuadrado. Pero si esa especialización impulsó a la comarca hasta alrededor de $1870^{8}$, a su crisis finisecular siguió la competencia recrecida por la expansión posterior del olivar por toda Andalucía, la sobreproducción vinícola y la falta de condiciones para extender sus regadíos. Aguilar no sólo padeció entonces la escasez de industrias y servicios modernos, perdió además la posición alcanzada en la agricultura provincial al acelerarse las transformaciones en los cortijos de la Baja Campiña en 1900-1930.

La información cuantitativa utilizada en este estudio procede mayoritariamente de documentación fiscal: catastros, listas cobratorias, repartos de consumos y otros materiales de juntas periciales municipales y provinciales, Delegación de Hacienda y Diputación Provincial. Las cartillas evaluatorias aportan cuentas para cada cultivo y calidad del suelo, con promedios generalmente decenales. En ellas se calculó el producto bruto durante la rotación y el detalle de sus gastos, siendo la diferencia entre ambos (un excedente bruto de explotación) el líquido imponible. La renta de la tierra se indicó en 1752 en las fincas arrendadas eclesiásticas y en todas en los amillaramientos y apéndices. Ese dato cru-

7. Los vecinos pasaron de 1.707 a 1.640 y 2.730 entre 1591, 1752 y 1837 , y los habitantes de 6.260 a 11.836 y 19.117 en 1752, 1845 y 1930. Aguilar-Moriles no se ha recuperado aún de la sangría migratoria de 1940-1980.

8. Entre los pueblos vecinos, Lucena poseía el cupo 16 de toda España, Cabra, el 30, y Montilla, el 32. Incluso el último sólo era superado por 15 capitales de provincia. (COMISIÓN DE ESTADísTiCA GENERAL DEL REINO, 1860: 277-278). 
cial, susceptible de comprobación documental, fijó la base para la tributación del rentista, quedando al colono cuanto restase del líquido imponible de la finca como beneficio de cultivo. He utilizado esas rentas tras contrastar su exactitud en contabilidades eclesiásticas y en muestras de contratos en protocolos notariales. También he empleado rentas de esos protocolos (1770-1771) y de todos los contratos de arriendo inscritos en el Registro de la Propiedad (1935-1959). En cada cultivo he promediado primero la renta de las parcelas de cada calidad y ponderado después las calidades por su extensión catastral, estuviesen o no arrendadas esas tierras. El jornal ordinario de varón adulto incluye el valor de su comida y corresponde a las tareas ordinarias, ponderadas por el número de peonadas que cada una solía ocupar. Tomo los jornales de cartillas evaluatorias, contabilidades privadas, Sociedad Económica de Amigos del País, Servicio Agronómico, convenios laborales y prensa histórica.

La selección de informaciones homogéneas para estudiar las desigualdades agrarias en el largo plazo -y trabajar con miles de contribuyentes en cada corte temporal- ha impuesto limitaciones en el campo de observación. La ocultación superficial fue reducida en los amillaramientos campiñeses, en contraste radical con las sierras cordobesas. Pero la ocultación pecuaria fue elevada y desigual por épocas y especies. Por ello, he excluido detallar el reparto social del ganado, aunque sumo el líquido pecuario a cada contribuyente al calcular la desigualdad. Por otra parte, el estudio aborda exclusivamente la evolución de las desigualdades agrarias. La información reunida sobre las actividades no agrarias es parcial, discontinua y heterogénea, e incorporar la propiedad urbana obligaba a acortar el período de estudio. He excluido los ingresos y patrimonio no agrario al estudiar la evolución de la desigualdad, aunque analizaré la posición de todas las familias hacia 1865 considerando esos y otros indicadores sociales.

Cuanto resta del artículo se estructura en cinco apartados. El segundo estudia las transformaciones agrícolas en Aguilar y contrasta su especialización olivarera con modelos interpretativos recientes. Del tercer al quinto apartado se analizan dimensiones diferentes de la desigualdad. El tercero estudia la distribución de la propiedad en 1752-1983, las clases emergentes y sus usos del suelo o la cambiante proporción de los excluidos. El cuarto se centra en el excedente bruto agrario, cuya desigualdad evolucionó con una cronología diferente a la distribución de la tierra, por influir en el excedente factores con trayectoria autónoma, como la renta de la tierra, el peso cambiante entre la explotación directa o por arrendatarios, o la existencia de pautas diferenciadas por grupos sociales en la especialización e intensificación de los cultivos. El quinto apartado incorpora los ingresos del trabajo, excluidos en las dos aproximaciones precedentes a la desigualdad y cruciales en Aguilar por el gran predominio de las peonadas asalariadas en el total de las agrarias. La distribución del ingreso agrario se estudia en tres ejercicios que identifican otra 
trayectoria de cronología bien distinta, en cuya definición fueron relevantes aspectos ya citados, así como las variaciones en la capacidad negociadora de los trabajadores. Finalmente, el sexto apartado aborda las conclusiones.

\section{LAS TRANSFORMACIONES AGRÍCOLAS EN AGUILAR}

La magnitud y precocidad de las transformaciones agrícolas en Aguilar se percibe con claridad en la redistribución de las superficies de cultivo (Cuadro 1).

\section{CUADRO 1}

Evolución de los usos del suelo en Aguilar y Moriles, 1752-1975

\begin{tabular}{lrrrrrrrr}
\hline & \multicolumn{4}{c}{ Superficie en ha } & \multicolumn{4}{c}{$\%$ en superficie cultivada } \\
Años & $\mathbf{1 7 5 2}$ & $\mathbf{1 8 1 8}$ & $\mathbf{1 8 7 2}$ & $\mathbf{1 9 7 5}$ & $\mathbf{1 7 5 2}$ & $\mathbf{1 8 1 8}$ & $\mathbf{1 8 7 2}$ & $\mathbf{1 9 7 5}$ \\
Usos del suelo: & ha & ha & ha & ha & \% & \% & \% & $\%$ \\
\hline Olivar & 3.738 & 4.183 & 10.791 & 11.354 & 26,1 & 35,6 & 66,0 & 62,6 \\
Viñedo & 561 & 591 & 1.045 & 4.305 & 3,9 & 5,0 & 6,4 & 23,7 \\
Cereal-leguminosas & 9.977 & 6.931 & 4.490 & 2.460 & 69,7 & 59,0 & 27,5 & 13,6 \\
Regadío y frutas & 43 & 42 & 21 & 20 & 0,3 & 0,4 & 0,1 & 0,1 \\
\hline Total cultivos & 14.319 & 11.747 & 16.347 & 18.139 & 100,0 & 100,0 & 100,0 & 100,0 \\
\hline Pastos & 860 & 174 & & & & & & \\
Monte & 948 & 2.230 & 2.182 & & & & & \\
Infructifero & 94 & 296 & 366 & 197 & & & & \\
\hline Total no cultivadas & 1.902 & 2.700 & 2.548 & 197 & & & & \\
Total catastrado & 16.221 & 14.447 & 18.895 & 18.336 & & & & \\
\hline
\end{tabular}

Fuentes: Catastro de Ensenada (1752); Cuaderno de Riqueza de Aguilar (1818); Instituto Geográfico Nacional (1872); Dirección General de la Producción Agraria (1974, 1977).

El cereal ocupaba en 1752 el 69,7\% de la superficie labrada (9/10 en tierras acortijadas, parte con encinas dispersas), por apenas el $27,5 \%$ en 1872 y la mitad un siglo después. Frente a ello, el olivar pasó del $26,1 \%$ al $66 \%$ en $1752-1872$, y sumado al viñedo escalaron del 30\% en 1752, al 40,6\% en 1818, 72,4\% en 1872 y 86,3\% en 1975.

Esos cambios radicales no deberían ocultar la importancia del olivar en 1752. El olivar en plantío compacto era común a todo tipo de titulares en Aguilar. La mayoría de los minifundistas poseía olivos como única propiedad, y compatibilizaba sus cuidados con el trabajo asalariado en los cortijos, entonces muy predominantes ${ }^{9}$. El olivar se concen-

9. 126 de los 233 vecinos seglares de Aguilar con menos de 4 fanegas (2,45 hectáreas) poseían oli- 
traba, no obstante, en explotaciones medias, bastantes de ellas con varias parcelas y con molinos aceiteros modestos, de modo que otros olivicultores acudían a once molinos que además de moler la Azeytuna a sus Dueños, lo executan a otros Particulares Cosecheros ${ }^{10}$ a maquila.

Según Infante (2012), el olivar andaluz se insertó aún por más de un siglo en prácticas de policultivo, con plantío aislado o intercalar, consumo familiar o local del aceite, y su leña fue motivo crucial para que los pobres lo plantaran. Prescindiendo de lo último, que estimo exagerado, su caracterización podría adecuarse a multitud de campesinos y a comarcas hoy olivareras con poquísimo olivar hacia 1750. Sin embargo, Andalucía conoció etapas de gran extracción de aceites desde el Imperio romano, de ahí que ese modelo socioecológico de inserción del olivo coexistiera con otros en comarcas que concentraban el grueso de los olivos y del aceite comercializado. Aguilar y siete pueblos vecinos reunían más de treinta mil hectáreas de olivar hacia 1750, cuyas lógicas de aprovechamiento divergían ampliamente del modelo propuesto por Infante. Por tanto, si bien su aportación es valiosa para el análisis ecoantropológico de numerosos cultivadores de olivos intercalares, desde otras perspectivas convendrá recordar que, de entre las comarcas especializadas ${ }^{11}$, sólo ésta acumulaba ya unos tres millones de olivos de varias patas, más que aquellos cultivadores juntos.

Las transformaciones incluyeron en Aguilar una intensificación general en los cultivos que puede seguirse en fuentes fiscales y agronómicas. El Cuadro 2 muestra el incremento de la proporción sembrada cada año en las superficies cultivadas de cereal (A) y de los rendimientos del trigo (B). El aspecto más singular fue el primero, por la extensión de rotaciones intensivas en las tierras que circundaban el núcleo urbano (ruedos) y en parcelas cada vez más alejadas. Para ello, fue crucial la aplicación creciente de trabajo y estiér-

vos exclusivamente. Conforme el olivar predominó en la contratación de asalariados, quienes poseían menos de 4 fanegas privilegiaron otros usos: el olivar ocupaba el $53 \%$ de sus tierras en $1752,47,3 \%$ en 1871 y $39 \%$ en 1983. Archivo Municipal de Aguilar de la Frontera (AMAF), Catastro de Ensenada (1752), Catastro de Rústica (1983) y Amillaramiento de 1871.

10. Catastro de Ensenada, Respuestas generales. El duque de Medinaceli poseía dos molinos que acumulaban 15 vigas y 53,9 hectáreas de olivar joven. Disfrutaba del privilegio del monopolio, pero vendía licencias para instalar molinos (71 catastrados en Aguilar) beneficiándose así del olivar al percibir el grueso del diezmo local y tributos sobre el comercio.

11. Catastro de Ensenada, Respuestas generales. Aguilar, Cabra, La Rambla, Lucena, Montalbán, Montilla, Monturque y Puente Genil-Miragenil. La mancha de olivar seguía por el marquesado de Estepa (Sevilla). Esos ocho pueblos contiguos ocupaban el 9\% de la extensión de Córdoba, pero casi igualaban la superficie olivarera de toda la provincia de Jaén, también concentrada espacialmente y contigua al olivar de Montoro (Córdoba) (SÁNCHEZ SALAZAR, 1989: 83-84). 
$\mathrm{col}^{12}$, y el avance de las leguminosas ${ }^{13}$ en alternancia con los cereales. En conjunto, las rotaciones más intensivas ocupaban 395 hectáreas en 1752, 851 en 1818 y 2.166 en 1872.

\section{CUADRO 2}

Intensificación de los cultivos en Aguilar ${ }^{*}$

\begin{tabular}{lcccccr}
\hline & A: \% sembrado en la superficie de & \multicolumn{3}{c}{ C: rendimiento medio del olivar } \\
& \multicolumn{3}{c}{ cereal y leguminosas } & & & \\
\hline años & 1750 & 1818 & 1880 & años & 1750 & 1885 \\
$\%$ & 40 & 56,2 & 73,6 & hl de aceite/ha & 1,6 & 4,42 \\
\hline \multicolumn{4}{c}{ B: rendimiento medio del trigo } & \multicolumn{2}{c}{ D: rendimiento medio de las viñas } \\
\hline años & 1750 & 1880 & años & 1750 & 1881 \\
hl/ha & 7,57 & 10,13 a 11,33 & hl de vino/ha & 4,74 & 11,15 \\
\hline
\end{tabular}

${ }^{\star}$ Se han ponderado las diferentes calidades y rotaciones por la extensión ocupada.

Fuentes: Catastro de Ensenada (1752); Cuaderno de Riqueza (1818); Amillaramiento (1871), Dirección General de Industria (1891); Gaceta Agrícola del Ministerio de Fomento (01/11/1889).

Esa vía de intensificación fue común en la agricultura mediterránea, pero extraordinariamente vigorosa en Aguilar. Hacia 1885 las rotaciones intensivas igualaban en extensión en el partido judicial al cultivo al tercio, el sistema extensivo mixto cerealícola-pecuario que ocupaba 9/10 de las superficies de sembradío de Aguilar en 1752 y que en 1930 predominaba todavía en la cercana Baja Campiña. Dados sus rendimientos casi dobles por hectárea recolectada y sus siembras sin intermisión, los ruedos superaron en Aguilar el producto agrícola de los cortijos desde mediados del siglo XIX y siguieron ampliando su ventaja. En ellos se consolidó un bastión de la pequeña explotación, complementario con el trabajo asalariado en olivos y viñas.

La viña era trabajada por asalariados, y sus labores se intensificaron por los favorables precios del afamado vino de Moriles (amontillado en Jerez). El olivar incorporó nuevas plantaciones, que rendían casi el doble que los viejos olivos centenarios, y recibió labores esmeradas en esa comarca de precoz especialización. El ingeniero provincial las puso

12. La densidad pecuaria creció en Aguilar algo menos que las superficies sembradas/plantadas, pero no existe correspondencia histórica precisa entre densidad ganadera, deyecciones y fertilización de los cultivos. La intensificación en la agricultura orgánica invirtió abundante trabajo en conservar las materias potencialmente fertilizantes y concentrarlas en usos agrícolas seleccionados. Los rebaños estacionados largas temporadas en pastos alejados, cuyas deyecciones se descomponían al sol, fueron reemplazados por mulos, cerdos y asnos, y el estiércol se preparaba en las casas para aplicarlo en los ruedos y al pie de los olivos.

13. Se sembraban 89 hectáreas al año hacia 1789 y 867 en 1818 , un $61 \%$ de ellas en los ruedos de siembra anual y en hazas más distantes, que sembraban entonces $2 / 3$ de su extensión. 
como modelo y les atribuyó los elevados rendimientos de Aguilar y de los partidos vecinos (Cabra, Lucena y Montilla), un 66\% superiores al resto del olivar provincial en 1885$1889^{14}$.

\section{CUADRO 3}

Evolución de la composición del producto agrícola total`

\begin{tabular}{|c|c|c|c|c|c|c|}
\hline \multicolumn{7}{|c|}{ \% en precios medios corrientes considerados en cada cartilla evaluatoria } \\
\hline Años & 1752 & 1818 & 1859 & 1881 & $\begin{array}{c}1900 \\
\text { oficial }\end{array}$ & $\begin{array}{c}1900 \\
\text { estimado** }\end{array}$ \\
\hline Cereales & 55,7 & 58,9 & 33,9 & 29,4 & 27,5 & 21,7 \\
\hline Ruedo & & $(24,6)$ & $(17,3)$ & $(16,9)$ & $(16,3)$ & $(16,6)$ \\
\hline Otros & & $(34,3)$ & $(16,6)$ & $(12,5)$ & $(11,2)$ & $(5,1)$ \\
\hline Olivar & 35,0 & 27,6 & 47,6 & 51,5 & 55,2 & 73,0 \\
\hline Viñedo & 7,2 & 9,9 & 15,9 & 16,4 & 14,6 & 2,9 \\
\hline Huerta & 2,1 & 3,7 & 2,6 & 2,7 & 2,7 & 2,4 \\
\hline Total & 100 & 100 & 100 & 100 & 100 & 100 \\
\hline
\end{tabular}

${ }^{\star}$ Dato del producto bruto de la fuente fiscal. Incluye subproductos y no resta reempleos.

${ }^{\star \star}$ Se estiman usos temporales alternativos porque en 1900 seguía constando la viña filoxerada.

Fuentes: Catastro de Ensenada (1752); Cuaderno de Riqueza (1818); Amillaramiento y apéndices de amillaramiento de Aguilar (1859, 1881, 1900).

Los cambios en cultivos, rendimientos y precios alteraron radicalmente la composición del producto agrícola amillarado (Cuadro 3). Los cereales perdieron 3/5 de su peso en el producto agrícola en 1752-1900, pese a la transformación de los ruedos. Frente a ello, el olivar y la viña escalaron hasta el $67,9 \%$ del producto agrícola amillarado hacia 1881 . Aunque si eliminamos defectos de esas fuentes, los cereales no llegaban hacia 1881 a 1/5 del producto final agrícola, deducidas las semillas. Menos aún en 1900, pese a la filoxera, pues la columna estimada no resta semillas, exclusivamente reemplaza por olivar las fincas plantadas antes de 1870 y añade algo de cereal en parte de las viñas filoxeradas.

El cambio de especialización y el crecimiento poblacional obligaron a importar el grueso de los granos de comarcas limítrofes. Mucho más lejos se consumieron los aceites y vinos locales, cuya extracción a puertos de embarque y grandes mercados (Cádiz, Málaga, Madrid) ocupó a gran número de arrieros hasta la llegada del ferrocarril. En conjunto, considerados los olivos y viñas en producción aún no amillarados, el producto agrícola real por habitante se elevó alrededor de un tercio de 1752 a 1880, algo menos de in-

14. Estos partidos acumulaban el 8,8\% de la extensión de Córdoba, el 37,4\% del olivar y un 49,8\% de sus cosechas (Gaceta Agrícola del Ministerio de Fomento, 01/11/1889). 
cluir la ganadería ${ }^{15}$. Una ganancia que concentraron los propietarios y elevó la desigualdad en la distribución del ingreso agrario.

\section{CAMBIOS EN LA DISTRIBUCIÓN DE LA PROPIEDAD DE LA TIERRA}

La distribución de la propiedad ha conocido notables transformaciones en Aguilar. A fines del Antiguo Régimen el número de propietarios vecinos aumentó con gran lentitud y creció la proporción de familias sin tierra. Posteriormente, la propiedad latifundista retrocedió intensamente y el número de pequeños propietarios creció con fuerza durante la Revolución liberal, la crisis finisecular y el franquismo tardío.

Los tres mayores patrimonios acaparaban en 1752 un $23,2 \%$ de las superficies catastradas, casi todas en cultivo como el resto del término. Pertenecían al duque de Medinaceli 1.373 hectáreas, a los propios catastrados en Aguilar $1.538^{16} \mathrm{y}$ al convento de Nuestra Señora de la Coronada, 913. La Iglesia acumulaba un peso infrecuente en la campiña, el $37,5 \%$ de la extensión catastrada pertenecía a 186 titulares eclesiásticos (2.492 hectáreas de titularidad patrimonial y 3.591 beneficial). Predominaba su cultivo directo y el olivar ocupaba un $22,1 \%$, pero muchas de las 628 parcelas eclesiásticas arrendadas (2.035 hectáreas) sustentaban numerosas pequeñas explotaciones ${ }^{17}$.

La distribución de la propiedad se había modificado bastante en el apeo de 1818, aunque las comparaciones son imprecisas por alteraciones en el término municipal. Lo más

15. La ganadería creció un 23,4\% en peso vivo en 1752-1865 en Aguilar, evolución similar a Andalucía $(+14,7 \%)$ o Extremadura (+26,9\%) (GARCía SANZ, 1994: 107-108). Su ocultación fue intensa en los amillaramientos y en Aguilar muy superior en las especies con reparto social menos excluyente. La densidad pecuaria en el partido alcanzaba $63,8 \mathrm{~kg} / \mathrm{ha}$ en el censo ganadero de 1865 , por 45,1 kg/ha amillarados en Aguilar en 1864 (AMAF, caja 552) y 30,9 kg/ha amillarados en todo el partido en 1881, sin caída real que lo justificase (Archivo Histórico Provincial de Córdoba [AHPC], Hacienda, leg. 2234). La ocultación ganadera era extendida y conocida. La Comisión Especial de Estadística Territorial de la provincia calculó la de Aguilar en un 56,8\% del líquido imponible pecuario en 1881, por 3,6\% en sus cultivos (AHPC, Hacienda, leg. 867). Sesgos similares sufren, al parecer, otras áreas estudiadas: Montefrío tenía 37 y $31,4 \mathrm{~kg} / \mathrm{ha}$ de peso vivo amillarado en 1852 y 1901 (GoNZÁLEZ DE MOLINA et al., 2011: 7) por $63 \mathrm{~kg} / \mathrm{ha}$ en el censo ganadero de 1865 su partido (términos de Montefrío e Íllora).

16. Parte de esos propios quedó después en otros pueblos del antiguo señorío, que también catastraron propios en 1752. Su distribución debe deducirse a partir de topónimos.

17. Los conventos de coronadas y carmelitas descalzas, y la fábrica parroquial aportaban $2 / 3$ de las tierras eclesiásticas arrendadas (AHPC, Hacienda, libros 337, 341). MATA (1987) destacó el elevado número de parcelas arrendadas por la Iglesia como singularidad comarcal frente a otras áreas de la Campiña Bética. 
significativo es que los propietarios de tierra vecinos decrecieron del $36,2 \%$ al $25 \%$ de las familias residentes en Aguilar en 1752-1818. El crecimiento demográfico acrecentó la proporción de los excluidos a fines del Antiguo Régimen y aumentó la presión para acceder a pequeñas parcelas en arriendo, una reclamación que apoyó el bando antiseñorial.

En los propios se produjeron cambios de uso. En 1752 aparecían con cultivo extensivo y en limitado número de fincas, lo que cambió por la presión popular aliada con las élites emergentes. Coincidiendo con las normativas reales favorables a los repartos de propios, en 1767 se realizó un sorteo de parte de esas tierras entre jornaleros de Aguilar (134,8 hectáreas entre 92 vecinos). Más amplio fue el reparto de 1788 (624,3 hectáreas entre 161 vecinos) (Naranjo, 1998: 146-152). Ambos coincidieron con fases de conflicto contra el duque de Medinaceli, señor jurisdiccional, mayor terrateniente local y perceptor de diezmos y otras cargas (Windler, 1997). En 1767 era personero y diputado del común Alonso Valenzuela y Valle, hacendado que lideró la Sociedad Económica de Amigos del País y el bando antiseñorial, y en 1788 esa facción reforzó su posición en la política municipal. Valenzuela se mostraba ante la burocracia estatal como defensor de los pobres. Proponía cederles pequeñas parcelas (1,22 hectáreas), de propios o en fincas privadas, y dotarles para iniciar sus labores con seis fanegas de trigo del pósito por fanega a sembrar, creando aldeas con sus ruedos como estrategia intensificadora. También animó a arrendar parcelas a otros grandes propietarios pues conocerán [...] la propia utilidad que les proporciona en la diferencia de ganar cada fanega (arrendada) en la actualidad cuando más sesenta rs. al año y estando de ruedo llegará a ciento ochenta lo menos ${ }^{18}$.

No todo quedó en proyectos. El arrendamiento de pequeñas parcelas perduró masivo casi un siglo. En cuanto a los propios, en 1818 estaban con rotaciones intensivas y repartidos entre gran número de vecinos con poca o ninguna tierra en propiedad. Todos se cedieron a censo enfitéutico en 1833 y 1837 a gran número de vecinos que accederían después a su propiedad. Aguilar figuró en la vanguardia de esos repartos de propios a censo, impulsados por los progresistas desde la Diputación, dejando los criterios de asignación al equilibrio de fuerzas municipal. Ese reparto definió para muchos vecinos pobres su principal ganancia con la Revolución liberal, por su posesión asegurada, reducida renta y posterior acceso a su propiedad. Constituyó una reivindicación vigorosa que al considerarse traicionada suscitó conflictos como el motín de Montilla al establecerse la re-

18. Archivo de la Real Sociedad Económica Matritense de Amigos del País (ARSEMAP), leg. 152, Memoria resumen de los trabajos de la Sociedad Económica de Aguilar desde su fundación, 14/03/1798. Grandes arrendatarios y rentistas se opusieron a la parcelación, como en otras áreas a la roturación; pero la presión de los pobres también contaba. En otra etapa convulsa (1842) incluso los Medinaceli buscaron aliados parcelando latifundios en aldeas de Lucena limítrofes con Aguilar. 
pública en $1873^{19}$, que dejó decenas de presos hasta fines de la década siguiente. Una de las experiencias de lucha de un bloque popular con nutrida militancia, que en el último cuarto del siglo XIX proporcionó a Aguilar-Montilla-Puente Genil las únicas actas parlamentarias federales por un distrito rural andaluz y un siglo después una duradera hegemonía socialista/comunista.

El patrimonio eclesiástico llegó mermado a la etapa liberal y desde 1836 se desamortizaron otras 1.965 hectáreas de ese origen en Aguilar. Por contraste con el reparto de propios, las subastas dificultaron el acceso a los vecinos pobres y se privatizaron indivisas fincas extensas. No obstante, el gran número de parcelas de algunos patrimonios eclesiásticos, su reventa y la parcelación de algunas grandes fincas ${ }^{20}$ permitirían participar gradualmente a cientos de vecinos pobres en la movilización general de esas tierras.

La desvinculación también contribuyó al retroceso del latifundismo antiguo. El marqués del Salar poseía en Aguilar 386 hectáreas en 1818 (incluidas 67,6 de olivar), 186 en 1852 y 141 en 1871. El marqués de Cabriñana poseía 222 hectáreas en 1818, 135 en 1871 y en 1881 sólo 71 hectáreas de olivar, plantadas dos décadas atrás. El marqués de Campo de Aras poseía 100 hectáreas en 1818 y 69 en 1871. Por excepción, el conde de La Jarosa poseía 92 hectáreas en 1818 y sus sucesores, los condes de Villanueva de Cárdenas, 136,5 en 1871-1881 (cortijo Monte Caicedo), aunque lejos de las 623 hectáreas catastradas en 1752 por esa familia. Muy posterior fue la disgregación del patrimonio de los Medinaceli, quienes superaron alguna generación sin división hereditaria y en 1871 poseían 2.020 hectáreas en Aguilar. La fragmentación comenzó en 1873 al fallecer el XV duque, se multiplicó al morir sin sucesión su hijo Carlos (II duque de Tarifa) al que heredaron once parientes en 1931, y aunque la reforma agraria paralizó ese reparto, el patrimonio acabó vendiéndose durante el franquismo.

La gran propiedad latifundista se hundió (Cuadro 4) al desaparecer las tierras eclesiásticas y de propios y desplomarse las de la nobleza y otros grandes terratenientes. En 1818 diez propietarios de más de 250 hectáreas acaparaban el 35\% del término y en 1983 ningún propietario individual alcanzaba ese umbral. Si prescindimos de los Medinaceli, los propietarios de más de 250 hectáreas poseían en 1818 un $79 \%$ más de extensión que en 1752 , un $45 \%$ en 1871 y un $13,5 \%$ en 1931 .

19. La Federación, 27/12/1873, en http://mdc2.cbuc.cat/cdm/ref/collection/federacion/id/459

20. El cortijo Téllez (286 ha) se parceló dos décadas después de su desamortización. Revendieron parcelas Ignacio Romero Cepeda (Osuna), que lo hizo también en muchos pueblos sevillanos, y Pedro Bedoya (Cádiz). 


\section{CUADRO 4}

Evolución de la gran propiedad en Aguilar *

\begin{tabular}{lccc}
\hline Años & $\begin{array}{c}\text { Número } \\
\text { de propietarios }\end{array}$ & $\begin{array}{c}\text { Hectáreas } \\
\text { que acumulaban }\end{array}$ & $\begin{array}{c}\% \text { de las } \\
\text { catastradas }\end{array}$ \\
\hline 1752 & 10 & 6.270 & 38,6 \\
1818 & 10 & 5.057 & 35,0 \\
1871 & 6 & 4.228 & 24,8 \\
1931 & 3 & 2.540 & 16,2 \\
1933 & 3 & 1.070 & 6,8 \\
1983 & $(2)^{\star \star}$ & $(812)^{\star *}$ & $(5,2)^{\star \star}$ \\
\hline
\end{tabular}

$\star$ Desde 1912 Aguilar no incluye el término segregado de Moriles (10,8\% de la extensión).

$\star \star$ Las cifras entre paréntesis indican que esas tierras pertenecían a grupos de hermanos que aparecían como titulares en común en el catastro.

Fuentes: Catastro de Ensenada (1752); Catastro de Rustica (1983); Cuaderno de Riquezas (1818); Amillaramiento (1871); información registral del Inventario para la Reforma Agraria (1931, 1933).

En paralelo a ese proceso se acrecentó el número de propietarios. Si en 1818 la proporción de vecinos con tierra en propiedad había descendido al 25\%, en 1871 poseía tierra un $39,5 \%$ de las familias, superando el nivel de 1752 . Un cambio indudable, aunque compensado en parte por el retroceso del pequeño arrendamiento, vigoroso aún dos décadas atrás, y por la privatización de patrimonios cuya renta sostenía servicios (beneficencia, gastos municipales, clero y templos). En adelante, el incremento de la proporción de familias con tierra progresó sin esos factores compensatorios, alcanzando un 46,6\% en 1881 , un $57,5 \%$ en 1914 y, tras un largo paréntesis, dio un nuevo salto en las décadas de la emigración en masa ${ }^{21}$.

Ambas tendencias atenuaron la concentración de la propiedad, pero el índice de Gini se redujo muy lentamente (Cuadro 5), pues la gran mayoría poseía superficies minúsculas. Frente a ello, aunque desaparecieron los antiguos latifundios, 37 individuos o conjuntos de hermanos que superaban las 100 hectáreas acumulaban 6.533 hectáreas en 1976 , el 40,4\% de la extensión de un término sin tierras incultas ${ }^{22}$.

Si la desigualdad se mantuvo elevada fue debido al ascenso de una nueva élite propietaria que aprovechó la enorme extensión de tierras movilizada por la Revolución. Entre los mayores beneficiados de la Revolución liberal destacan descendientes de familias hidalgas, labradoras de antiguo. Antonio de Toro Valdelomar, segundo contribuyente de

21. Un $80,5 \%$ en 1983 , pero con inclusión de forasteros que la fuente no distingue, siempre muy minoritarios.

22. AMAF, leg. 906. Incluyo hermanos con explotaciones independientes. 
Aguilar por territorial en 1831, primero en 1852-1871 y décimo en la provincia, descendía de hidalgos que escalaron a la élite local a fines del Antiguo Régimen. En 1818 su madre poseía 528 hectáreas de cultivo en Aguilar y labraba 465, valorándose su patrimonio en 1,8 millones de reales (como el del duque de Medinaceli en Aguilar). A ello incorporó Antonio el legado de su suegro, acaudalado labrador arrendatario. En 1831 poseía fundamentalmente olivar y viña, cuatro molinos y un lagar, que acrecentó con compras en Aguilar, La Rambla y Córdoba. Antes y durante su ascenso a la élite provincial arrendó y labró grandes cortijos, como Fuente Alcalde ( 235 ha) del convento de la Coronada, que cultivaba cuando lo adquirió en la desamortización en 1841, o el cortijo del Ingeniero (960,6 ha) de los propios de la capital en 1856. En 1852 poseía en Aguilar 1.091 hectáreas (entre ellas 382,5 de olivar y 28,5 de viña), 6 molinos aceiteros, 60 vacunos, 83 equinos, 289 cerdos y 200 ovejas. También destacó en la política (Espino, 2009), como diputado provincial de Unión Liberal (1858-1869) y más tarde presidente del Partido Conservador en Aguilar.

\section{CUADRO 5}

Evolución de la distribución de la propiedad en Aguilar, 1752-1983

Distribución por frecuencias en fanegas de tierra $(0,6121 \mathrm{ha})^{\star}$

\begin{tabular}{|c|c|c|c|c|c|c|c|c|}
\hline \multirow[t]{2}{*}{ Fanegas } & \multicolumn{2}{|c|}{1752} & \multicolumn{2}{|c|}{1818} & \multicolumn{2}{|c|}{1871} & \multicolumn{2}{|c|}{1983} \\
\hline & $\begin{array}{c}\mathrm{n} .^{0} \text { de } \\
\text { propietarios }\end{array}$ & $\begin{array}{c}\% \text { de la } \\
\text { tierra }\end{array}$ & $\begin{array}{c}\mathrm{n} .{ }^{0} \text { de } \\
\text { propietarios }\end{array}$ & $\begin{array}{c}\% \text { de la } \\
\text { tierra }\end{array}$ & $\begin{array}{c}\mathrm{n} .{ }^{0} \mathrm{de} \\
\text { propietarios }\end{array}$ & $\begin{array}{c}\% \text { de la } \\
\text { tierra }\end{array}$ & $\begin{array}{l}\mathrm{n} .{ }^{0} \text { de } \\
\text { propietarios }\end{array}$ & $\begin{array}{c}\% \text { de la } \\
\text { tierra }\end{array}$ \\
\hline 0,01 a 1 & 155 & 0,36 & 103 & 0,31 & 281 & 0,72 & 483 & 1,17 \\
\hline 1,01 a 2 & 107 & 0,62 & 83 & 0,54 & 244 & 1,45 & 677 & 3,73 \\
\hline 2,01 a 4 & 92 & 1,03 & 95 & 1,19 & 222 & 2,38 & 573 & 6,11 \\
\hline 4,01 a 8 & 98 & 2,09 & 106 & 2,62 & 215 & 4,34 & 308 & 6,46 \\
\hline 8,01 a 16 & 84 & 3,66 & 112 & 5,65 & 143 & 5,89 & 217 & 9,39 \\
\hline 16,01 a 32 & 69 & 6,09 & 73 & 7,06 & 118 & 9,44 & 158 & 13,62 \\
\hline 32,01 a 64 & 53 & 9,54 & 51 & 10,48 & 73 & 12,29 & 82 & 14,17 \\
\hline 64,01 a 128 & 37 & 12,54 & 20 & 7,96 & 43 & 13,50 & 45 & 14,59 \\
\hline 128,01 a 256 & 14 & 9,21 & 22 & 16,98 & 26 & 17,02 & 29 & 19,80 \\
\hline 256,01 a 512 & 18 & 22,88 & 14 & 22,33 & 9 & 11,55 & 5 & 5,90 \\
\hline 512,01 a 1024 & 3 & 8,74 & 2 & 6,39 & 2 & 4,34 & 2 & 5,07 \\
\hline 1024,01 a 2048 & 1 & 5,63 & 3 & 18,49 & 1 & 5,22 & & \\
\hline Más de 2048 & 2 & 17,61 & & & 1 & 11,87 & & \\
\hline Total & 733 & 100,00 & 684 & 100,00 & 1.378 & 100,01 & 2.579 & 100,00 \\
\hline Gini & & 0,8869 & & 0,8627 & & 0,8573 & & 0,8130 \\
\hline
\end{tabular}

${ }^{\star}$ Se mantiene el escalado en fanegas utilizado por Naranjo (1998) en su estudio sobre Aguilar en 1752.

Fuentes: Catastro de Ensenada (1752); Catastro de Rústica (1983); Cuaderno de Riquezas (1818); Amillaramiento (1871). 
También hubo patrimonios acumulados por grandes arrendatarios de pueblos limítrofes o surgidos de fortunas de origen comercial y financiero ${ }^{23}$. Los hermanos García de Leaníz llegaron a Aguilar en 1813 procedentes de Laguna de Cameros. José Eleuterio poseía en 1818 un comercio de tejidos con tres empleados que movía un capital de 200.000 reales y generaba 12.000 de beneficio anual. Por entonces poseía 10 hectáreas y un molino aceitero, arrendaba otras 10,4 hectáreas de olivar, más 64,8 del gaditano Juan Soprani junto a su hermano Manuel. Éste poseía otro comercio mayor aún y en 1831 contribuía por 59 hectáreas de cereal, 37 de olivar, 11,4 de viña, molino y lagar. La escalada a la élite terrateniente la efectuó el hijo del primero, José Marcelo, quien adquirió fincas desamortizadas en Montilla, La Rambla y Aguilar, ascendiendo al número 28 como contribuyente por territorial en la provincia. En Aguilar era el decimotercero mayor contribuyente en 1847, el cuarto en 1852 con 218,4 hectáreas y su patrimonio siguió ampliándose al tiempo que ocupó tres veces la alcaldía con los moderados (1857-1868). En 1879 dejó en herencia 360 hectáreas en Aguilar, fundamentalmente olivar, con 5 molinos y 40 hectáreas de viña con su lagar (en 1931 una descendiente poseía 406 hectáreas).

He subrayado los cargos políticos desempeñados por esa burguesía ascendente, pues estimo que contribuyeron a su enriquecimiento en esa época de transformaciones. Toro Valdelomar arrendaba grandes fincas de bienes nacionales y adquirió tierras desamortizadas como el grueso del grupo. Sus influencias le sirvieron en diciembre de 1854 para que la Diputación anulase la reclamación del Ayuntamiento de Aguilar por consumos (4.000 reales) y recargo de rústica (3.602), y en 1871 para que la junta pericial recalificase sus fincas rebajando su líquido imponible en Aguilar en 27.680 reales, permitiéndole un ahorro anual equivalente al salario bruto de cuatro gañanes de cortijo ${ }^{24}$. Circunstancias semejantes concurren en el segundo mayor contribuyente en 1871, Alonso Tiscar Córdoba, también labrador y político de familia hidalga. En 1837 los trabajadores obtuvieron el reparto de los propios de Aguilar, pero la dehesa Pimentada (la mayor finca de propios catastrada en 1752, situada en Puente Genil) continuó arrendada por el alcalde progresista de Aguilar y diputado provincial, Francisco López-Berrio, y acabó incorporada al patrimonio familiar. Su yerno, A. Tiscar Córdoba, poseería el cortijo Pimentada ${ }^{25}$,

23. Entre quienes comenzaron en Aguilar como arrendatarios, Juan de Mata Burgos Jiménez, en 1881 primer contribuyente $(415,4$ hectáreas, principalmente haciendas de olivar, 4 molinos aceiteros y un lagar). Entre los financieros, Antonio Murga y sus sucesores (Madrid), condes de Moriles desde 1921.

24. Toro empleaba a 16 sirvientes domésticos y 41 trabajadores agrarios permanentes en Aguilar (AMAF, caja 45-2).

25. Pimentada tenía 509 hectáreas cultivadas (491 en 1752), 61 de monte arbolado y 40.370 reales de líquido imponible (AHPC, leg. 366, Amillaramiento de Puente Genil, 1871). El protagonismo político familiar perduró. En 1870 era alcalde de Aguilar Manuel Tiscar López-Berrio, y su hermana Jo- 
aparte de sus fincas en Aguilar. Derrotado el carlismo, la acumulación de poder políticoeconómico y las instituciones forjadas por el liberalismo conservador acabarían por imponerse al progresismo popular y reforzar la desigualdad. Entre otras formas, definiendo los períodos y procedimientos de desamortización, condicionando quienes adquirían fincas que parceladas habrían alcanzado además remates superiores.

Los propietarios enriquecidos -cuya tipología he esbozado- retrasaron el hundimiento de la gran propiedad latifundista. Pero por debajo de ellos creció lo acumulado por otro colectivo que vivía holgadamente de sus tierras. Quienes poseían de 16 a 256 fanegas equivalían a casi un décimo de las familias vecinas y pasaron de acumular un 37,4\% del espacio catastrado en 1752, a un 52,3\% en 1871 y un 62,2\% en 1983.

La heterogeneidad del colectivo aconseja subdividirlo. Quienes poseían de 64 a 256 fanegas (de 39,2 ha a 156,7 ha) no eran latifundistas, pero con la especialización local y explotación directa alcanzaban en Aguilar hacia 1870 ingresos comparables a los propietarios de la Baja Campiña de cortijos varias veces más extensos. Su número creció menos que las familias vecinas y su participación en la superficie catastrada aumentó regularmente, pasando del $21,8 \%$ en 1752 al 34,4\% en 1983, lo que encumbró su posición económica. En un segmento inferior figuraban labradores acomodados o rentistas con 16 a 64 fanegas (de 9,8 ha a 39,2 ha). Su número creció en medida similar al de las familias vecinas y acumularon una porción creciente de las tierras catastradas (15,6\% en 1752, $21,7 \%$ en 1871 y $27,8 \%$ en 1983). Quedaban lejos de la élite, pero constituían el grueso de las familias acomodadas y su ascenso contribuyó al mantenimiento de las desigualdades.

Muy por debajo de ellos, la minúscula propiedad se multiplicó y elevó su participación conjunta en la superficie catastrada. Quienes poseían menos de 2 fanegas pasaron de acumular el $0,85 \%$ de la superficie catastrada en 1818 , al $2,17 \%$ en 1871 y $4,90 \%$ en 1983, y cuantos no llegaban a 8 fanegas ( 4,9 ha) del $4,7 \%$ al $8,9 \%$ y $17,5 \%$, respectivamente. Una progresión que acabó por reducir intensamente la proporción de familias no propietarias y mantuvo estable la extensión por minifundista.

\section{EVOLUCIÓN DE LA DISTRIBUCIÓN DEL EXCEDENTE AGRARIO}

Las contribuciones directas por rústica calcularon el líquido imponible en cuentas de cultivo restando del producto bruto los costes. El resultado, un excedente bruto de explo-

sefa era esposa del diputado, brigadier y hacendado local Rafael Carrillo de Albornoz. 
tación ${ }^{26}$, deducía como coste las rentas del trabajo, que constituían el grueso del ingreso para la mayoría de la sociedad. De ahí que su distribución alcanzase cotas elevadísimas de desigualdad, muy superiores a las del ingreso, que encuentra su límite en la necesidad de asegurar la subsistencia de cada persona.

Ese líquido se calculó con criterios semejantes durante largo tiempo y nos servirá para estudiar la trayectoria de la distribución del excedente agrario (Gráfico 1), que pondera ganados y tierras de acuerdo con el margen capturado por cada agente (explotador directo, rentista o colono) según cultivos, calidades, precios y renta de la tierra cambiantes. La renta fue para Hacienda la información más relevante, susceptible de contrastación documental y base de las evaluaciones sintéticas del catastro contemporáneo. Cuestión distinta es la actualización de las valoraciones. Los grandes municipios béticos, con cupos elevados y contribuyentes poderosos también entre los grandes arrendatarios, reiteraron esas cuentas durante el siglo XIX aunque no hubiese cambios drásticos en precios, técnicas o rendimientos y su detalle permite contrastar sus datos con otras fuentes. Paradójicamente, el catastro moderno suprimió las cuentas de cultivo de ámbito municipal y realizó pocas actualizaciones cuando la inflación y el cambio técnico las hizo más precisas. Por ello, mostraré su distribución, pero en el siglo Xx evitaré contrastar sus líquidos tardíamente actualizados con la renta o jornales de cada período.

La desigualdad en la distribución del excedente agrario se redujo en Aguilar a largo plazo en medida semejante al reparto de la tierra, pero con cronología diferente. Los numerosos cortes temporales estudiados permitirán establecer su evolución.

De 1818 a mediados de siglo se redujo levemente la concentración en la distribución del excedente (índices 85 y 83). Como ese descenso de la desigualdad (Gini) coincidió con el aumento de la proporción de vecinos que accedieron al cultivo y se incorporaron como contribuyentes, la trayectoria resulta más significativa ${ }^{27}$. Esa reducción de la desigualdad obedecía a factores reales: a) al fuerte retroceso de la élite tradicional, por pérdida de tierras y su retraso en plantar olivos; b) a las ganancias de los contribuyentes medios, que plantaron olivos, redondearon sus patrimonios con tierras desamortizadas y arrendaron bienes nacionales antes eclesiásticos en cultivo directo; c) al incremento del

26. No se calculó así el líquido por urbana (2/3 del alquiler, deduciendo $1 / 3$ por arreglos a cargo del rentista y períodos sin arrendar), en la pecuaria el método fue cambiante, y en la industria y comercio se optó por indicadores más burdos y una presión fiscal media muy inferior.

27. Mido la desigualdad entre contribuyentes, no en el conjunto de la población. La adición de gran número de contribuyentes con líquidos minúsculos -aunque antes fueran proletarios estrictos y ese cambio redujese la desigualdad global- habría elevado significativamente el índice de Gini de permanecer igual todo lo demás. En 1958-1983 también se minusvalora el declive de la desigualdad. 
excedente de muchos pequeños cultivadores, por ampliación del área con rotaciones intensivas y depreciación de las rentas que satisfacían (propios a censo y otros bienes nacionales con rentas inmóviles, con inflación) ${ }^{28}$. Las décadas revolucionarias coincidieron en Aguilar con mejoras significativas para muchos cultivadores pobres, como la supresión del diezmo y la imputación al rentista del grueso de la contribución de inmuebles ${ }^{29}$, y una leve mejoría/recuperación en los jornales reales.

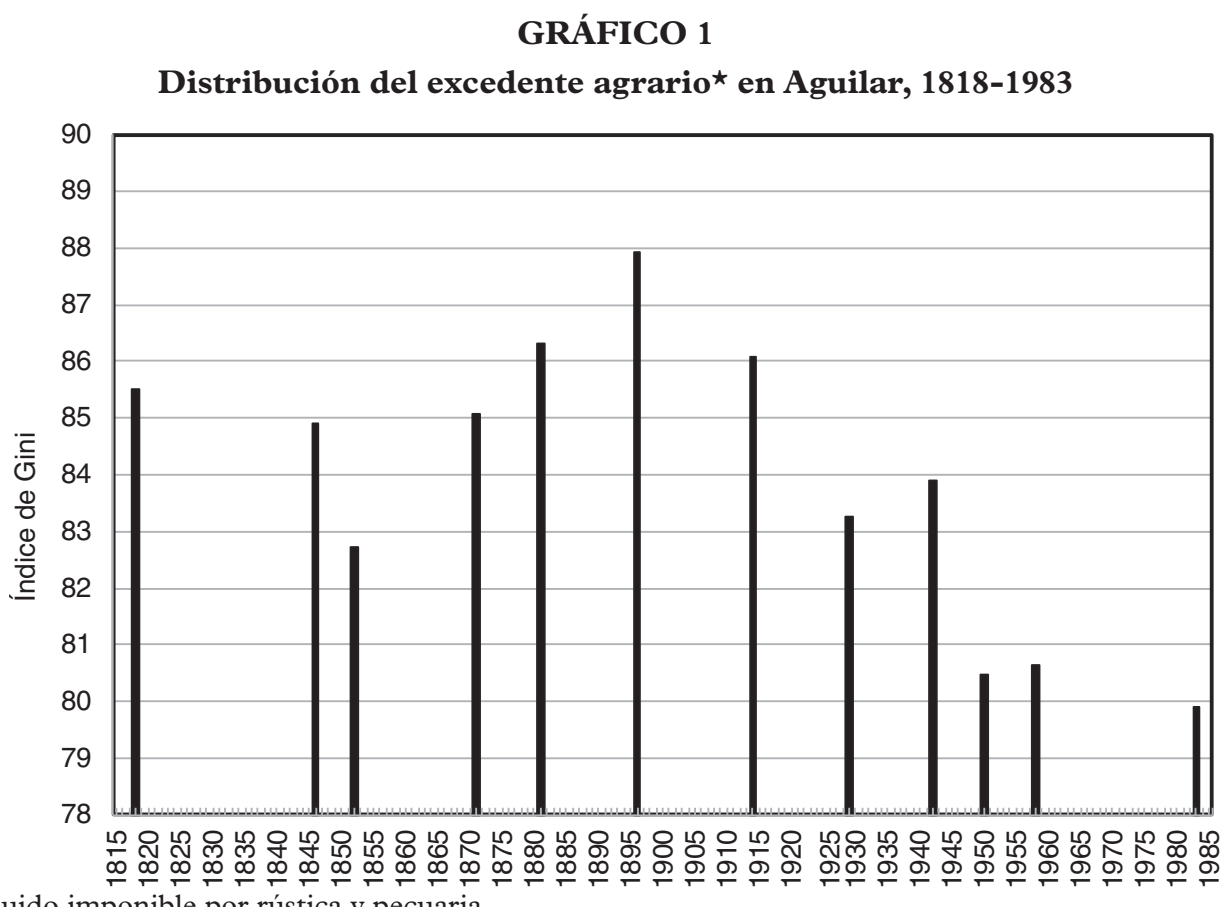

^Líquido imponible por rústica y pecuaria.

Fuente: elaboración propia a partir de amillaramientos, catastro y listas cobratorias de los años citados.

Más tarde, en 1852-1896, se produjo una escalada en la desigualdad que elevó el índice de Gini de 83 a 88. Ello obedeció en parte a la creciente explotación directa de sus fincas por la nueva élite, que dejó en sus manos todo el excedente, desapareciendo muchos

28. La renta de 32 parcelas del convento de la Coronada de Aguilar convertida a grano pasó de 100 en 1807-1820, a 121,6 en 1821-1833 y 79,3 en 1834-1854. Una bajada no infrecuente en parcelas de bienes nacionales en la comarca. El peso de propios y bienes eclesiásticos en las pequeñas parcelas arrendadas, junto con la ampliación del ruedo a tierras más distantes, redujo el diferencial entre la renta por hectárea pagada por los pobres en los sembradíos intensivos y por los ricos labradores en los cortijos de 6,9 a 4,6 veces de 1818 a 1850 .

29. Un vector progresivo minusvalorado de la contribución de inmuebles de 1845 (LÓPEz EsTUDILLO, 2008: 491, 512), que los rentistas desnaturalizaron en algunas áreas. 
arrendatarios acomodados por contraste con la Baja Campiña, donde perduraron en los cortijos que dominaban su paisaje. Pero principalmente respondía al excedente muy superior que les proporcionaron sus olivos y viñedos ${ }^{30}$ respecto de los usos precedentes de esas fincas. Si bien un hacendado-labrador de Aguilar con 80 fanegas de olivar nuevo y 20 de viña no era un latifundista, pues poseía 61,2 hectáreas, su excedente agrario equivalía hacia 1865 al de cortijos de la Baja Campiña con 250 a 400 hectáreas. Adicionalmente, esas plantaciones multiplicaron la riqueza patrimonial de esa élite ${ }^{31}$. Atendiendo a ese aspecto, la desigualdad creciente en este período parecería sustentar la propuesta de Piketty, con la objeción por circularidad que suele criticársele, pues el elevado valor alcanzado por olivos y viñas dependió mucho más de la renta extraordinaria que proporcionaron que de la inversión en su plantación.

La depreciación del vino y la filoxera redujeron la desigualdad en Aguilar. La viña aportó en las décadas finales del siglo XIX de $1 / 6$ a $1 / 5$ del líquido por rústica y pertenecía a ricos contribuyentes. Decenas de ellos poseían explotaciones de 6 a 25 hectáreas de viña dotadas de lagar en los mejores pagos de tierras albarizas, cuando los últimos mil contribuyentes por propiedad rústica (72,6\% del total) apenas acumulaban 39,5 hectáreas en $1871^{32}$. No obstante, sus efectos en la desigualdad aparecieron retrasados en la contribución $^{33}$, y coinciden en mi gráfico con la segregación de Moriles en 1912, que separó mucha viña del término de Aguilar.

Por el contrario, los cambios técnicos del primer tercio del siglo xx ejercieron efectos desigualitarios en la campiña. La mejoría en los rendimientos en los cortijos y ampliación de sus sembradíos, por la fertilización mineral complementaria y las mejoras en sus rotaciones y labranza, elevó la productividad en esas fincas y mucho más su renta de la tierra. En la Baja Campiña cerealista ello enriqueció a sus élites -incluidos los aristócratas rentistas- y acrecentó la desigualdad en el ingreso. En Aguilar y el suroeste de Córdoba el olivar no conoció transformaciones equiparables, y eran minoría entre sus grandes con-

30. Un lagar con 16 hectáreas de viña pagaba una renta similar a un cortijo de 250 hectáreas con sus edificios hacia 1870. La renta por hectárea en las viñas multiplicó la de los cortijos por 4,5 en 1752, 9,8 en 1818 y 15,8 en 1870 .

31. El valor de los olivos y viñas superó ampliamente su peso en la superficie y en la producción local. En 1818 una hectárea de olivar valía en promedio 3,34 veces lo que una de tierra acortijada, la de viña 7,48 y la de ruedo 4,97 veces (AHPC, Cuaderno de Riqueza de Aguilar).

32. La viña aportó el $24,2 \%$ de todo el líquido por rústica a la decila de mayores contribuyentes en 1871 por un $9,1 \%$ al resto, con ínfimas aportaciones en los pobres. La viña recuperó las superficies prefiloxéricas en el partido de Aguilar en 1917-1924, pero aportaba al producto agrícola la mitad que hacia 1880.

33. Por no actualización de valores catastrales, más grave en las viñas filoxeradas en los años noventa que contribuyeron como viña hasta 1902-1903. 
tribuyentes quienes poseían cortijos todavía y se beneficiaron. Pero la competencia de los cortijos bajocampiñeses impulsó allí la desigualdad al desvalorizar las parcelas de ruedos y el fruto que los pobres obtenían del intenso trabajo aplicado en su fertilización orgánica y rotaciones ${ }^{34}$. Más adelante, la decreciente desigualdad de la década de 1950 pudiera deberse a sesgos favorables a los ricos en las valoraciones catastrales. Por último, el avance de la pequeña propiedad y su protagonismo en la expansión vitícola de 1960-1980 redujo la desigualdad.

No puedo precisar cómo afectaría a la trayectoria de la desigualdad el incluir otras rentas patrimoniales y excedentes de actividades no agrarias. Pero realizaré una aproximación global a esa desigualdad hacia 1865 manipulando los valiosos indicadores que se emplearon para repartir el impuesto de consumos (Cuadro 6). Las 22 familias vecinas más ricas, las primeras afectadas por el reparto, reunían más del $30 \%$ del líquido por la contribución de inmuebles (rústica, urbana y pecuaria), la de comercio e industria y otras utilidades conocidas, y la decila más rica acumulaba alrededor del $70 \%$. La extraordinaria desigualdad que ello refleja responde a la exclusión de los ingresos del trabajo -salvo el de algunos profesionales-, así como a especificidades de esa sociedad: en primer lugar, la única industria significada, los molinos aceiteros, estaba acaparada por los mayores contribuyentes por territorial hasta la irrupción en el siglo xx de las fábricas aceiteras (Salgado y Carbonell); en segundo lugar, quienes obtenían remuneración elevada en actividades no agrarias aplicaban su ahorro a adquirir inmuebles; y, por último, incorporar la propiedad urbana amplió la base contribuyente, pero afectó limitadamente a la desigualdad, pues los obreros poseían habitáculos de ínfimo valor, gran parte de ellos en calles de composición social tan homogénea que eran excepción quienes contribuían por un asno o una parcela.

El resultado de la ponderación de esos líquidos imponibles y otros signos de posición social, que fueron seleccionados para repartir consumos a quienes contrataban asalariados justificándolo por la alimentación aportada frecuentemente como parte de la remuneración laboral, fue que al $1 \%$ más rico de las familias vecinas contribuyentes le correspondió el 20,8\% de los consumos repartidos en 1865 entre los vecinos. Cada familia del $1 \%$ poseía un ingreso anual próximo a 25 veces el de la familia mediana, pero en el reparto cargó en promedio con 1.626 reales, más de 125 veces lo repartido a la familia mediana y 100 veces cuando se añade el impacto en cada familia de la fracción del tri-

34. La renta por hectárea en ruedos más hazas sueltas multiplicaba por 3,33 la de los cortijos en 1868-1870 y por 1,61 en 1939-1942. La renta de cortijos cordobeses en 1700-1935, en LóPEZ EsTUDILLO (2002, 2007). 


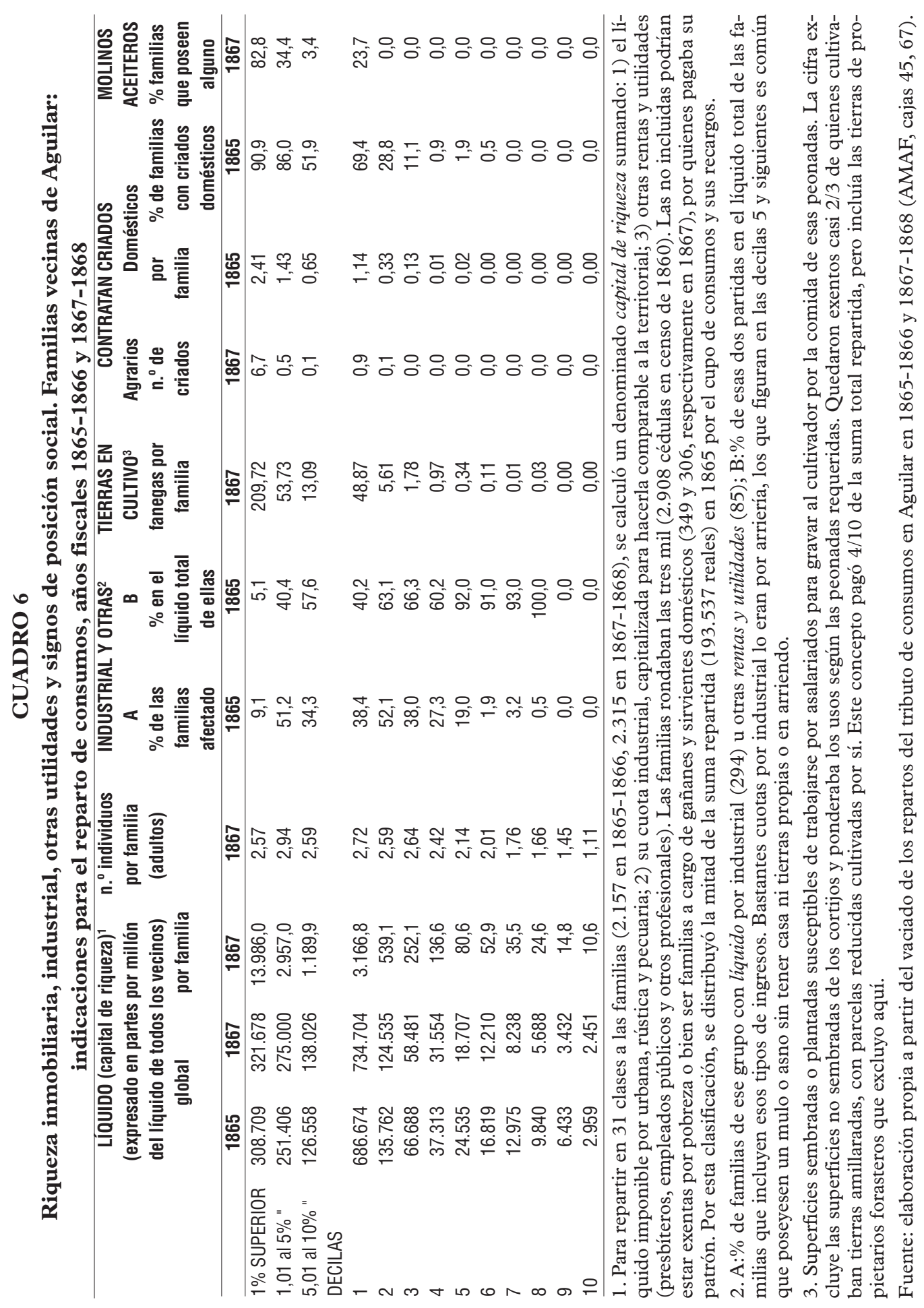


buto concertada con minoristas que encareció varios productos de consumo ${ }^{35}$. No me detendré en el sesgo progresivo de esa distribución de tan impopular tributo, pues los criterios de reparto fueron cambiantes. Sí subrayaré nuevamente las repercusiones del conflicto sociopolítico. La protesta continuada contra los consumos, muy regresivos en su definición normativa, no solo provocó motines en años de hambre y desesperación. Aparte de su supresión intermitente por progresistas y republicanos, condujo a alteraciones sustanciales y perdurables en su reparto local entre pobres y ricos, vecinos y hacendados forasteros, incluso con gobiernos conservadores.

\section{GRÁFICO 2}

Participación de los mayores contribuyentes en la riqueza rústica imponible en Aguilar, 1818-1983. Mayores contribuyentes en número equivalente al 1\% de las familias, 1 al $5 \%$ y 5 al 10\%

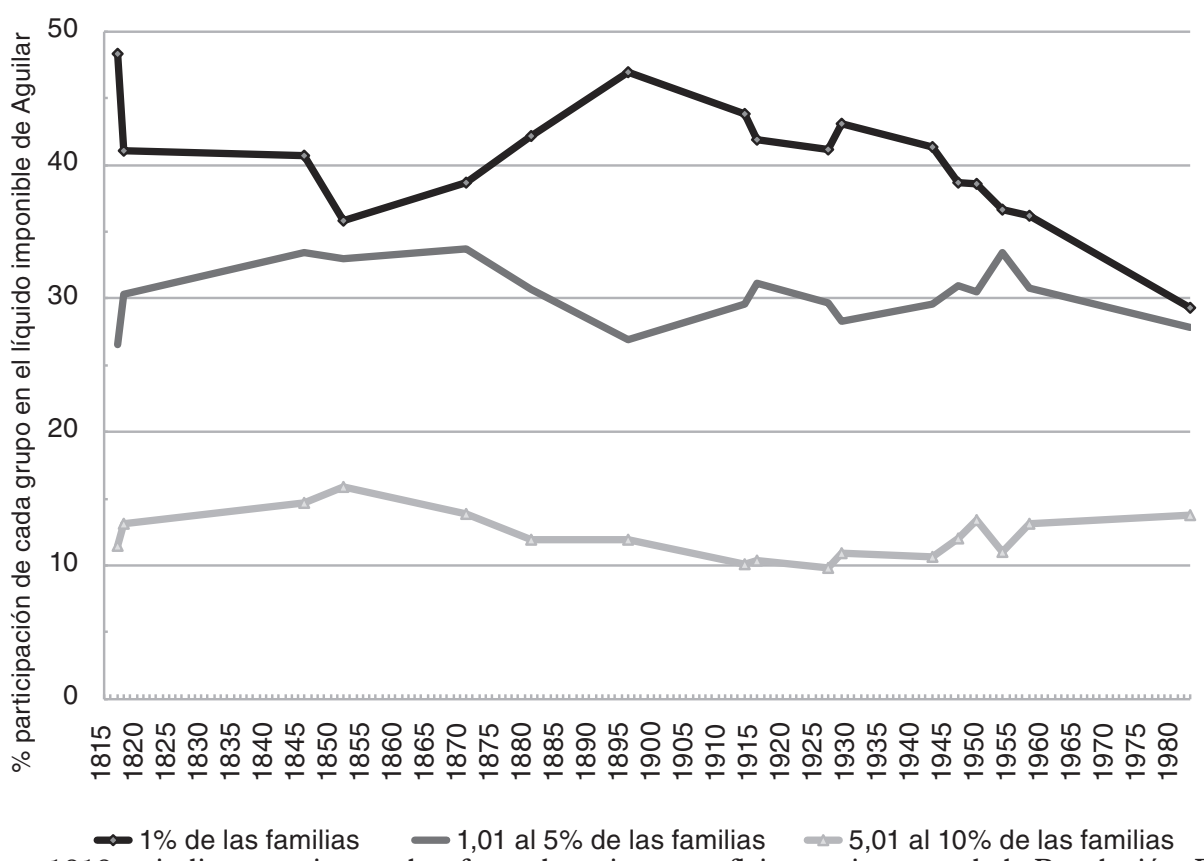

Nota: en 1818 se indica un primer valor, fuera de serie, que refleja otro impacto de la Revolución. El 1\% concentraba en 1818 un $41,1 \%$ del excedente agrario, pero un $48,3 \%$ de añadir el diezmo percibido por el duque de Medinaceli, ya deducidos costes de recaudación, ingreso agrario individual sujeto a la contribución de Garay.

Fuentes: elaboración propia a partir de catastros, Cuaderno de Riqueza (1818), amillaramientos, apéndices de amillaramiento y listas cobratorias por rústica y pecuaria de Aguilar.

35. La junta pericial estimó el gasto por familia de cada clase en cada producto concertado. Dada la pirámide clasista de anchísima base de ese reparto, la familia mediana pertenecía a la clase 30 . $^{\text {a }}$, la penúltima. 
Volvamos a la distribución del excedente agrario. La distorsión en los índices de desigualdad por la conversión paulatina de proletarios en microcontribuyentes por rústica es preciso superarla incorporando a todos los vecinos. Calcularé para ello la porción del excedente agrario acumulado por varios grupos de mayores contribuyentes, incluidos ahora forasteros, equivalentes a un porcentaje de todas las familias residentes en Aguilar. Dado que el sector agrario mantuvo su proporción en la actividad y reunía aún en 1960 al 74\% de los activos varones, la evolución del excedente agrario concentrado por los mayores contribuyentes equivalentes al $1 \%$ de todas las familias, constituye un indicador relevante, fácil de interpretar y que no prescinde de la masa jornalera.

\section{GRÁFICO 3}

Número de peonadas/ha requeridas y usos del suelo (\%), según la dimensión de cada propiedad en Aguilar, 1983

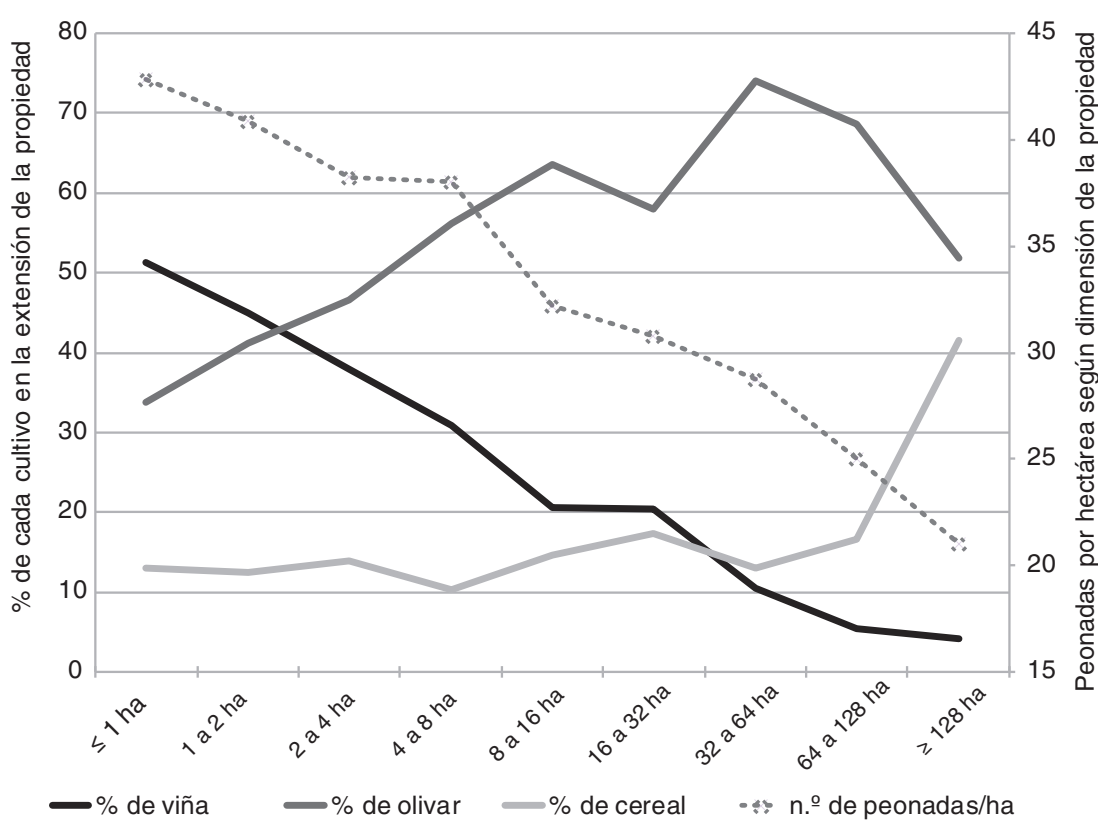

Fuente: elaboración propia a partir del vaciado del Libro de Cédulas de Propiedad del Catastro de Rústica de Aguilar de la Frontera (AMAF, 1983).

Los contribuyentes equivalentes al 1\% de las familias de Aguilar aminoraron su participación en el excedente agrario durante la Revolución y la acrecentaron en la segunda mitad del siglo XIX (Gráfico 2), alcanzando en 1896 hasta un 47\%. Más tarde, su parte fluctuó en un nivel elevado en 1914-1943 (de 43,8\% a 41,1\%), descendiendo después progresivamente hasta el $29,3 \%$ en 1983 . La distancia era enorme con quienes suponían hasta el $5 \%$ de las familias, que reunían por familia alrededor de una quinta parte que la élite del $1 \%$, y con los comprendidos entre el $5 \%$ y el $10 \%$, que poseían alrededor de una 
quinceava parte. No obstante, su diferencial con la élite fue cambiante y ello proporcionó mayor estabilidad a la elevadísima participación conjunta de esa decila superior en el excedente agrario: entre el $84,5 \%$ y el $88,8 \%$ de 1818 a 1896 ; del $83,5 \%$ al $80 \%$ en 1914 1958; y un descenso final al $71 \%$ en 1983 .

Esa reducción final de la desigualdad en la distribución del excedente obedeció a la acción de los pobres, quienes aprovecharon una coyuntura favorable a sus vinos para multiplicar por cuatro la superficie vitícola prefiloxérica (4.305 hectáreas en Aguilar-Moriles en 1977), plantando viñas fuera de los pagos vitícolas históricos, propiedad de familias acomodadas. Una reacción que podría interpretarse como defensiva, por pretender acrecentar su ingreso agrario bruto aumentando las peonadas trabajadas en lo propio (Gráfico 3) ${ }^{36}$ para mitigar la intensa subocupación, cuando la mecanización gradual de las labores en el olivar hundió el empleo e impulsó a emigrar a millares de vecinos.

\section{LA EVOLUCIÓN DE LA DESIGUALDAD EN EL INGRESO AGRARIO}

La dificultad principal para precisar la distribución social del ingreso agrario radica en los ingresos del trabajo. Determinar su evolución depende de conjeturas que he rehuido. Además de series del jornal común, exige supuestos arriesgados sobre el número de peonadas trabajadas por adulto, la aportación de mujeres y niños ${ }^{37}$, los destajos realizados por vecinos, los acarreos y obradas para terceros con ganado propio y otros aspectos afectados por cambios notabilísimos en tan largo período. El trabajo asalariado mantuvo su predominio, pero con desigualdades significativas entre familias trabajadoras y con el recurso dispar a otras actividades, que hacemos mal en acumular. Unas eran cruciales para los más pobres (ocupación permanente de niños en los cortijos, trabajo asalariado de mujeres y niñas, caza y rebusca furtivas) y otras las concentraban quienes poseían parcelas, algún animal de tracción y medios para alimentar regularmente cerdos o gallinas. Quien poseía una hectárea de ruedo hacia 1860 podía superar en alrededor del $25 \%$ el ingreso anual de quien trabajase idéntico número de jornadas/año, y esa diferencia podía doblarse o más de poseer una mula y trabajar obradas para terceros, engordar animales de corral y poseer vivienda en propiedad. Un diferencial que se traducía en mayor consumo y posible ahorro, y parcialmente en reducir el trabajo asalariado de mujer e hijos.

36. Los 618 contribuyentes que exclusivamente poseían viña reunían 698 hectáreas y aplicaban 59,9 peonadas/ha, según el catastro en 1983. Dos décadas antes, cuando se habían disparado las plantaciones, la viña cumplía mejor aún esa función, pues empleaba 124,6 peonadas/ha (Convenio laboral agrario de Aguilar, Boletín Oficial de la Provincia de Córdoba, 05/12/1962).

37. López EsTUdillo (2006: 108). 
Las tres aproximaciones que siguen a la distribución del ingreso agrario han evitado supuestos arriesgados y no integran varios de esos aspectos. Como era previsible, incorporar los ingresos del trabajo reduce los niveles de desigualdad frente a la distribución de la tierra o del excedente. Pero el contraste más interesante aparece en su trayectoria, por el crecimiento hasta mucho después de la desigualdad en el ingreso.

En primer lugar estimaré la magnitud agregada de la renta de la tierra y los ingresos del trabajo para descubrir el sentido de la redistribución del ingreso agrario. El Catastro de Ensenada evaluó el producto agrícola y forestal, censó a jornaleros y labradores, citó un presunto jornal e imputó un líquido imponible al trabajo considerando 120 peonadas/año. Esas convenciones sobre los ingresos laborales proyectan una sociedad ficticia, con desigualdades incompatibles con la baja productividad por agricultor y el gasto necesario para la subsistencia ${ }^{38}$. Los trabajadores agrarios adultos aparecían con ingresos imponibles de 300 reales/año, o inferiores, equivalentes al 55\% del valor de la comida recibida por un gañán de cortijo en su remuneración mixta anual ${ }^{39}$. Por otra parte, los 1.125 activos agrarios del catastro en Aguilar, trabajando 120 peonadas/año, proporcionarían sólo 9,43 peonadas por hectárea cultivada, $2 / 5$ de las usuales en los cortijos y mucho menos respecto de otros cultivos.

La operación piloto del catastro permite decodificar convenciones. En Fernán Núñez se detalló el ingreso anual por asalariado agrario en subgrupos con distintos niveles de habilidad, tareas y peonadas/año. Sus 828 asalariados agrarios ganaban en promedio 853 reales/año. Dividiendo su ingreso anual por 365 obtuvieron su ingreso diario que, redondeado, citaron como jornal en las respuestas generales. El método fue general en la comarca y similares sus jornales catastrales. Si a los acomodados 50 labradores por su mano de Aguilar les imputamos su ingreso/día según las respuestas generales de Aguilar (3,5 reales $\times 365=1.275,5$ reales/año) y a los restantes 1.075 activos agrarios, los 853 reales/año promedio del cercano Fernán Núñez, las rentas laborales de los vecinos sumarían 980.750 reales $^{40}$. Un $14,4 \%$ aportado por 140 labradores, hortelanos u otros por cuenta propia y el $85,6 \%$ por los jornaleros del catastro, parte de ellos con parcelas o ganaderos. Si calculamos la renta de la tierra de todo el término multiplicando la renta de cada cultivo y calidad (muestra: 500 fincas arrendadas) por su respectiva superficie catastral,

38. Contradictorio con su frontera de desigualdad (MILANOvic, Lindert \& Williamson, 2011; WILLIAMSON, 2012a).

39. AHPC, libro 438.

40. Adopto el supuesto del texto para evitar los «jornales» redondeados (2,5 o 3 reales/día), atendido su error en Fernán Núñez. Multiplicando el ingreso/día catastral de cada categoría en Aguilar por 365 resultan 1.044 .713 reales. 
la renta de la tierra aportaría un $37,5 \%$ y el trabajo un $62,5 \%$ de la suma de ambos ingresos $^{41}$.

Ciento veinte años después la especialización olivarera estaba culminando, las rotaciones intensivas de ruedos ocupaban 5,5 veces su extensión de 1752 y la productividad por ocupado había experimentado un moderado pero significativo avance, descendiendo levemente el jornal común. Con la cartilla evaluatoria de 1863 y los usos del suelo medidos por el Instituto Geográfico Nacional (1872) pueden estimarse las necesidades de trabajo y su valor, y el amillaramiento de 1871 informa de la renta de la tierra. Operando con esos datos, el valor agregado del trabajo agrario -asalariado o no- había crecido menos que la renta de la tierra. Fundamentalmente se debía a la extensión de olivares y viñedos, cultivos en que la renta capturaba una porción del producto bruto y del ingreso agrario muy superior a la de otros usos -aunque inferior que en 1818 . Si sumamos el valor del trabajo y la renta de la tierra en Aguilar en 1752 y 1865, la aportación de la renta pasó del $37,5 \%$ al $44 \%$ y la del trabajo se redujo como mínimo del $62,5 \%$ al $56 \%{ }^{42}$. Si se considera la intensificación en peonadas/hectárea, ello implica que el jornal común se hundió respecto de la renta de la tierra por hectárea.

En segundo lugar estimaré la distribución del ingreso agrario hacia 1865. Los 30 mayores contribuyentes, vecinos y forasteros equivalentes al $1 \%$ de las familias de Aguilar, concentraban un 38,7\% del líquido imponible agrario (renta de la tierra, utilidades del cultivo y pecuaria) y otro $33,7 \%$ los 121 contribuyentes siguientes. Juntos, esos 151 contribuyentes, equivalentes al $5 \%$ de las familias vecinas, reunían un $72,4 \%$ del excedente agrario y alrededor del $36,4 \%$ del ingreso agrario, incluidas las rentas del trabajo -ya restada la contribución territorial-, gracias a concentrar la propiedad del $80 \%$ de las tierras del término y explotar directamente un $69,4 \%$ (año 1871).

El Cuadro 7 refleja la desproporción entre el ingreso agrario de esos 151 contribuyentes y distintas familias tipo (así como el de los 113 que equivalían al 5\% del total de familias que vivían del sector agrario). Cada partícipe de la élite (1\%) ingresaba, ya restada la contribución territorial, 27,5 veces lo que una familia jornalera, o 25,2 veces lo que la familia mediana ocupada en el campo (por trabajo, renta y utilidades de explotación). A su vez, el siguiente 4\% (121 contribuyentes) multiplicaba por 6 y por 5,5 el ingreso agrario de esas dos familias. Es cierto que muchas familias obreras obtenían recursos

41. Tal suma no totaliza la renta bruta agraria, pues el catastro no imputó utilidad alguna al arrendatario y omitió el trabajo de mujeres, ancianos y menores de 16 años.

42. El declive real sería superior, por la exclusión citada de mujeres y otros en 1752. En 1865 incorporo el trabajo de los ganaderos, omitido en la cartilla. 
excluidos de las cuentas de cultivo (entre ellos, caza y aprovechamientos furtivos, servicio doméstico, limpieza de ropas y encalado de paredes por trabajadoras). Sin embargo, la desigualdad cambiaría poco, pues no he imputado a los ricos ganancias laborales y en actividades no agrarias, y quienes realizaban actividades complementarias al jornal mejor remuneradas (acarreos y obradas con yunta propia) estaban muy por encima de la familia mediana agraria, pues incluso las especies ganaderas con menores exclusiones sociales (asnal y porcino) apenas alcanzaban al 31\% de las familias en el censo ganadero.

\section{CUADRO 7}

\section{Reparto social de la renta agraria en Aguilar hacia $1865^{\star}$}

(renta agraria antes de impuestos $=\mathbf{1 0 . 0 0 0}$ )

\begin{tabular}{|c|c|c|c|c|c|}
\hline & \multicolumn{2}{|c|}{ Importe bruto } & \multicolumn{3}{|c|}{ Id. deducida contrib. de inmuebles } \\
\hline & Total & Subtotal & Por familia & Subtotal & Por familia \\
\hline Excedente (renta+ beneficios de cultivo) & 5.746 & & & & \\
\hline \multicolumn{6}{|l|}{-Mayores contribuyentes equivalentes } \\
\hline al $1 \%$ de las familias totales & & 2.224 & 73,67 & 1.668 & 55,25 \\
\hline al $4 \%$ siguiente de las familias totales & & 1.936 & 16,03 & 1.452 & 12,02 \\
\hline al $1 \%$ de las familias agrarias & & & 87,86 & & 65,89 \\
\hline al $4 \%$ siguiente de familias agrarias & & & 19,67 & & 14,76 \\
\hline -Resto de contribuyentes por rústica y pecuaria & & 1.586 & 1,09 & 1.190 & 0,82 \\
\hline Contribuyente mediano & & & 0,58 & & 0,44 \\
\hline Familia mediana ocupada en el sector & & & 0,24 & & 0,18 \\
\hline Rentas del trabajo agrario & 4.254 & & 2,01 & 4.254 & 2,01 \\
\hline Total & 10.000 & & & & \\
\hline
\end{tabular}

Número de veces en que el ingreso agrario de los mayores contribuyentes, ya restada la contribución rústica y pecuaria, multiplicaba el ingreso agrario de diversas familias tipo

\begin{tabular}{lccc}
\hline & $\begin{array}{c}\text { Familia } \\
\text { jornalera }\end{array}$ & $\begin{array}{c}\text { Familia mediana } \\
\text { ocupada en campo }\end{array}$ & $\begin{array}{c}\text { Familia mediana } \\
\text { contribuyente por rústica }\end{array}$ \\
\hline -Mayores contribuyentes equivalentes & & & \\
al 1\% de las familias totales & 27,45 & 25,19 & 22,57 \\
al 4\% siguiente de las familias & 5,97 & 5,48 & 4,91 \\
al 1\% de las familias agrarias & 32,73 & 30,05 & 26,92 \\
al 4\% siguiente de familias agrarias & 7,33 & 6,73 & 6,03 \\
\hline
\end{tabular}

* Supuestos asumidos: a) el $5 \%$ más rico no trabaja personalmente en el campo; b) un 70\% de las familias vive del trabajo en el sector agrario con idéntico ingreso laboral, sea asalariado o autoempleado; c) el trabajo de los vecinos fuera del término equivale al de los forasteros en Aguilar; d) el 75\% de las familias son agrarias ( $70 \%$ activas agrarias $+5 \%$ rentistas).

Fuentes: elaboración propia a partir de la Cartilla Evaluatoria (1863) y Amillaramiento de Aguilar (1871).

En tercer lugar, estudiaré la trayectoria de la desigualdad expresada en el índice renta de la tierra/jornal. El jornal común expresado en trigo era en 1931-1933 alrededor del 182\% del existente en 1752, tras permanecer largas etapas por debajo del nivel de 1752 y au- 
mentar desde 1900, cuando la productividad creció en toda la campiña sin destrucción de ocupación, y la organización e influencia política de los trabajadores, las alternativas de empleo y las oportunidades migratorias debilitaron la posición dominante de los grandes labradores.

\section{GRÁFICO 4}

Jornal agrícola común y renta de la tierra en Aguilar, 1745-1942

(base 100 en 1745-1750; valores deflactados por el precio del trigo)

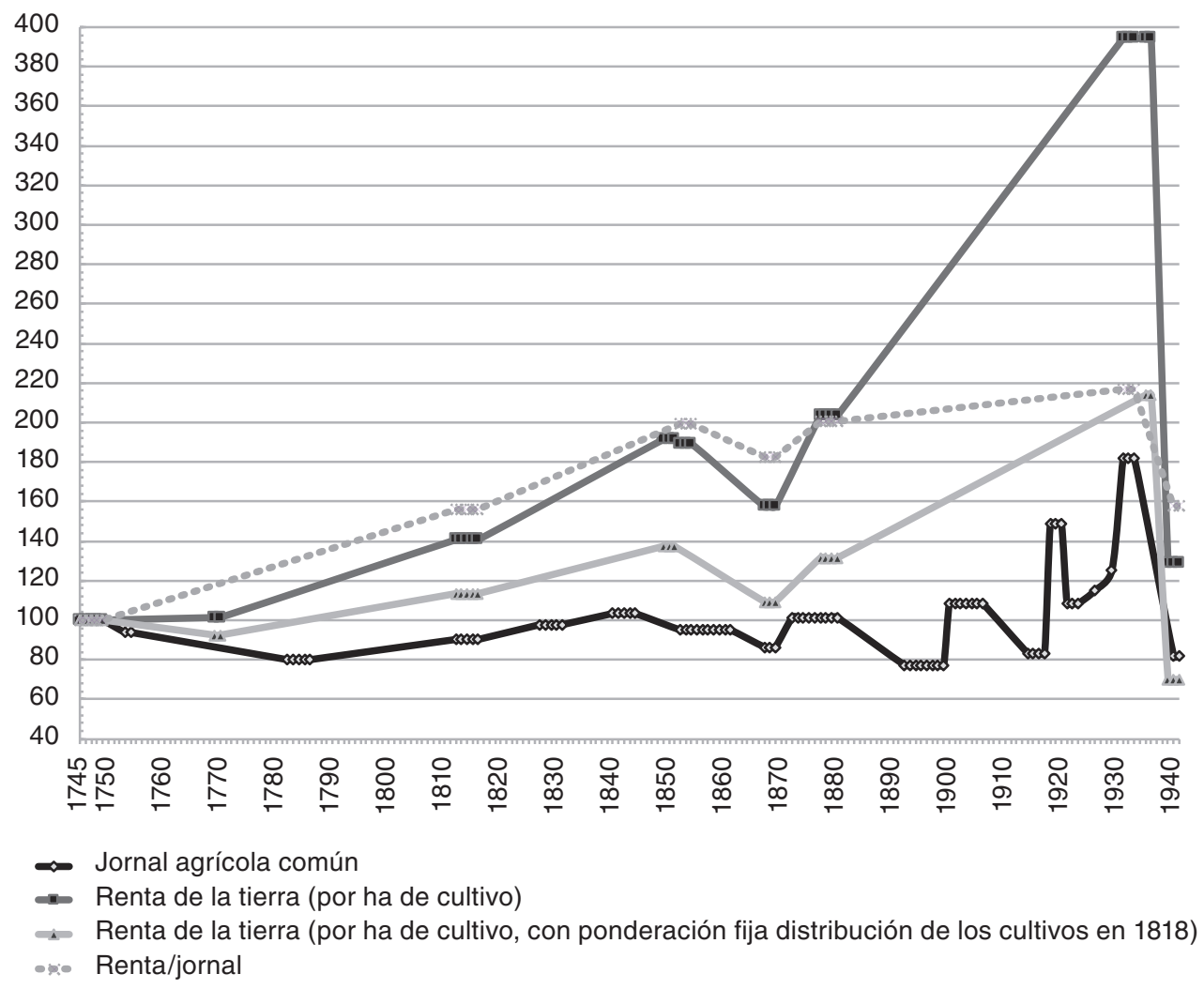

Fuentes: elaboración propia a partir de la renta de la tierra del Catastro de Ensenada, Cuaderno de Riquezas, amillaramientos, protocolos notariales y Registro de la Propiedad, y jornales de cartillas evaluatorias, informadores del Servicio Agronómico, convenios-tarifas laborales, contabilidades y prensa histórica.

La renta por hectárea cultivada se elevó al 395\% entre 1752 y 1935 (deflactada por el precio del trigo), tras alcanzar cotas superiores en 1925-1930. Esa elevación puede descomponerse en dos factores (Gráfico 4): a) la subida de la renta fijando la ponderación de cada cultivo según su superficie en 1818 elevó la renta media al $214 \%$; b) cuanto resta hasta el 395\% se debe al cambio de especialización y renta muy superior de cuanto pasó a cultivarse con olivar, viña o ruedos frente al predominio del cereal al tercio en 1752 . La 
aportación proporcional del segundo factor fue crucial hasta 1850-1880, muy influido por la cronología precoz del avance de esos cultivos y rotaciones intensivas en Aguilar, que se atenuó cuando la crisis finisecular golpeó al olivar (Zambrana, 1987) y la viña, y los precios y transformaciones técnicas posteriores beneficiaron más al cereal extensivo que a las especializaciones locales.

El crecimiento de la desigualdad con el índice renta/jornal se concentró en 1752-1850, alcanzó valores máximos en la Primera Guerra Mundial y la dictadura de Primo de Rivera (información no incluida en el gráfico), descendió con la República, manteniendo hacia 1935 un 10\% por encima del nivel de 1850 o 1880, y cayó con fuerza en el franquismo.

La renta descendió en la posguerra por la caída de rendimientos, la inflación y las posibles presiones al rentista, y perdió por corto tiempo lo ganado desde 1752. Además, el nivel real divergió con fuerza en perjuicio de las rentas fijadas en metálico, muy mayoritarias, y muchos rentistas asumieron la gestión directa para capturar las ganancias del mercado negro. La renta se recuperó mejor en el olivar que en otros cultivos, pero en 19461947 rondaba un $40 \%$ de su nivel real de 1935 , y un $62 \%$ en $1955-1959^{43}$. También el jornal se hundió a los niveles inferiores de los dos siglos precedentes, y no recuperó su poder adquisitivo de la Segunda República ${ }^{44}$ hasta 1964.

La renta por hectárea de olivar pasó de equivaler a 32 jornales en 1870 y 27 hacia 19331935, a 10 en 1962 y 8 en $2009^{45}$. Adicionalmente, también hundió su participación en las cosechas y en la renta agraria. Si la renta de la tierra suponía en Aguilar un $45 \%$ del producto anual en los olivares hacia 1870, rondaba un 30\% en 1940-1943, un 16-20\% hacia 1955-1962 $2^{46}$, antes de la mecanización y el empleo masivo de inputs externos al sector, y un nivel similar a fines de la reciente edad de oro del olivar, que exacerbó modelos de explotación no sostenibles. No obstante, la renta de la tierra en relación al jornal o la cosecha perdió calidad como indicador de desigualdad social antes de que se multipli-

43. Las rentas de 1935-1959 en dos tomos del Registro de la Propiedad de Aguilar. Informo del olivar pues de los cultivos minoritarios en Aguilar poseo pocos contratos en varios años, perdiendo representatividad mis series ponderadas de renta de la tierra.

44. AMAF, leg. 197. El ingreso por familia jornalera se recuperó antes debido al fuerte incremento del trabajo agrícola femenino entre 1931-1936 y 1960-1964.

45. Los 10 jornales corresponden al olivar medio provincial (Delegación del Ministerio de Hacienda en Córdoba, Cuentas catastrales, 1962).

46. La renta media del olivar en Aguilar en 1955-1959 equivalía al 20\% del producto/ha del olivar provincial. En 1962 los ingenieros del Catastro estimaron al olivar medio provincial una renta de la tierra equivalente al $15,9 \%$ de su producción (27,6\% en los mejores y $10,3 \%$ en los inferiores), y ratios renta/producción inferiores a los decimonónicos también en otros cultivos (Delegación del Ministerio de Hacienda en Córdoba). 
caran las inversiones en equipo y los gastos corrientes fuera del sector, o se hundieran las peonadas/hectárea y por ocupado al año. La superficie arrendada sería reducida (un 10\% del total en 1964 según la junta pericial) y el rentista sería frecuentemente un agente minoritario e incluso singular, como ancianas o familiares de quienes seguían cultivando ${ }^{47}$.

En suma, la ratio renta/jornal descendió en el olivar a un $25 \%$ entre 1870 y 2009, frente al descenso a un $20 \%$ de ese indicador en Inglaterra en 1842-1936. Pero la cronología seguida en Aguilar por la desigualdad no respalda los importantes efectos que la teoría neoclásica atribuía al comercio internacional en ese proceso. La especialización exportadora de Aguilar debería haber impulsado al alza la remuneración relativa del factor abundante utilizado intensivamente en su producción (trabajo) frente al factor escaso (la tierra). De haberse cumplido la previsión de Williamson a partir de esa teoría, la ratio renta/jornal debiera haber iniciado su descenso más de medio siglo antes de cuando comenzó. Paradójicamente, su descenso se concentró cuando la economía española iniciaba su aislamiento excepcional de los mercados internacionales ${ }^{48}$.

A pesar de ese descenso relativo de la renta de la tierra y de los reducidos márgenes de explotación que estiman las cuentas agronómicas oficiales, han persistido fuertes diferencias de ingreso entre el jornalero sin tierra y el empresario-labrador (titular de renta de la tierra, beneficio de cultivo, PAC e ingresos por su trabajo menos afectado por la subocupación ${ }^{49}$. Cuestión diferente es el nivel y evolución de la desigualdad en el ingreso entre todos los vecinos, cuando se transformaron las instituciones y el sector agrario perdió preeminencia. En 2007, antes de la agudización reciente de la desigualdad, Aguilar mantenía elevadas desigualdades en el ingreso (Hortas \& Onrubia, 2014) ${ }^{50}$, aunque, si aceptamos las declaraciones del IRPF, se había reducido radicalmente la participación del $1 \%$ respecto de 1865 , en un contexto previo a la crisis actual, con jornales mínimos, transferencias públicas, presión sindical, mayor acceso a la tierra y desagrarización creciente.

47. En una explotación de Aguilar cuya renta era casi idéntica a la más frecuente del olivar de almazara provincial (JUNTA DE ANDALUCÍA, 2009: 17), ésta equivalía al 17\% de su cosecha media y al 19\% del valor añadido agrícola más la PAC, considerado el reparto de la PAC acordado entre las partes. 48. Williamson (2012a: 195-204; 2012b: 210-231, 287-318, 495, 508).

49. He reconstruido las cuentas de 2002 y 2009 de una explotación con más de cincuenta hectáreas de olivar (segundo centil por extensión cultivada). Su ingreso, incluida la PAC, multiplicaría el del jornalero sin tierras, como en el siglo XIx, imputando al obrero 100 jornales/año más el subsidio. Los rendimientos fueron semejantes al promedio provincial, pero sus costes/ha inferiores a las estimaciones agronómicas, incluidas amortizaciones y trabajo familiar valorado al jornal común.

50. El 1\% con mayores ingresos concentraba un 7,02\% de la renta imponible en 2007 y el quintil con mayor ingreso un 50,4\%. Por su Gini $(0,47)$, Aguilar figuraría en una ordenación decreciente en el centil 27 entre las poblaciones andaluzas y el 29 en las españolas de más de 5.000 habitantes (http://www.fedea.net/renta/desigualdad.html). 


\section{CONCLUSIONES: DESIGUALDADES CON TRAYECTORIASY MOTIVACIONES ESPECÍFICAS}

En los apartados precedentes he adoptado una perspectiva que atribuye la evolución de las desigualdades a múltiples causas, con pesos e interinfluencias cambiantes en el tiempo. Entre las teorías disponibles opté por una selección muy restrictiva e instrumental de dos que destacaban aspectos centrales en las transformaciones de Aguilar:Williamson, por vincular especialización con cambios en la desigualdad, y Piketty, por relacionar la mayor concentración patrimonial con la creciente desigualdad en el ingreso.

En Aguilar hubo coincidencia temporal en el siglo XIX entre su especialización, que requirió inversiones considerables, y el incremento de la desigualdad en el ingreso. Pero no atribuyo nexos mecánicos o universales entre especialización, dotación de factores y desigualdad, que siguió una evolución opuesta a la prevista por Williamson. La relación en Aguilar dependió del protagonismo de grupos acomodados en el impulso del olivar cuando era la mejor de las granjerías de la época. La plantación de olivos y viñas fue crucial en la trayectoria local de la desigualdad cuando la renta de la tierra en ambos cultivos alcanzó una proporción doble o más en sus cosechas que en huertas, cortijos y ruedos. Por ello, el incremento global de la renta de la tierra descansó crucialmente en el cambio de especialización (Gráfico 4) y después decayeron sus efectos locales sobre la desigualdad.

Tampoco la acumulación de riqueza explica suficientemente ese incremento de la desigualdad en el ingreso. El valor patrimonial elevadísimo que alcanzaron viñas y olivos obedecía a las extraordinarias rentas que producían más que a la inversión en su plantación, lo que introduce circularidad en la relación causal propuesta por Piketty. Por otra parte, las plantaciones requerían fundamentalmente trabajo, que muchos pobres subocupados poseían en abundancia. De ahí que quienes carecían de propiedad consiguieran en otros contextos socioinstitucionales apropiarse parcialmente de las mejoras y reducir ciertos índices de desigualdad (Tello \& Badia-Miró, 2015). También en Aguilar la pequeña propiedad, muy ampliada desde 1752, protagonizó una importante expansión vitícola hacia 1960-1980 que moderó la desigualdad en un contexto global de desagrarización de la economía. Pero la trayectoria local de la desigualdad obedeció a muchas otras causas: al moderado éxito de los pobres en su acceso a la propiedad durante la Revolución; al declive posterior de la cesión en arrendamiento; al impacto sobre sus jornales, por migraciones estacionales y permanentes, de la debilidad de las transformaciones agrarias decimonónicas en comarcas vecinas y su dinamismo posterior en el siglo Xx; o a la cambiante capacidad de negociación de sus trabajadores con ciclos de empoderamiento y de represión. 
El estudio ha destacado a fines del Antiguo Régimen la fuerte alza de la exclusión en el acceso a la propiedad y acentuación de la desigualdad en ingreso (el índice renta de la tierra/jornal pasó de 100 a 156 en 1752-1818). También la inflexión que provocó la Revolución liberal en variados indicadores y procesos, aunque algunas mejoras se frenaron o perdieron después.

El hundimiento del latifundismo, el crecimiento del número de propietarios y la reducción del porcentaje de desposeídos conocieron intensidades muy superiores a las del conjunto de Andalucía desde la Revolución liberal; aunque los propietarios acomodados no latifundistas ampliaron su peso en la distribución de la propiedad y el limitado descenso del índice de Gini relativiza mucho la significación de esas transformaciones.

La desigualdad en la distribución del excedente agrario alcanzó cotas muy elevadas y aumentó hasta fines del siglo XIx. Una divergencia cronológica frente a la distribución de la tierra que debió menos al alza de la renta posterior a la Revolución-que fue menor en las explotaciones arrendadas por los pobres o inexistente como fracción de sus cosechasque a pautas diferenciadas por grupos sociales en la especialización e intensificación de los cultivos, y a la adopción generalizada de la explotación directa por la nueva élite.

Por último, la desigualdad en la distribución del ingreso agrario creció hasta mucho después, e incluso superaba todavía en 1935 los máximos alcanzados en 1850-1880 (índice renta /jornal). Tras la guerra civil, el hundimiento de la renta fue superior incluso al de los jornales (salvo participación en estraperlo, cuando la renta era en especie), y ese indicador no se recuperó en adelante, lo que explica la ruina de algunos rentistas. No obstante, el limitado peso de la cesión en arrendamiento, el intenso subempleo o la PAC reclaman aproximaciones alternativas para precisar mejor las fases e intensidad del declive de la desigualdad apuntado por el índice renta/jornal.

En definitiva, las tres dimensiones de la desigualdad investigadas muestran trayectorias cronológicas claramente diferenciadas y causalidades específicas. Un resultado que alerta sobre la debilidad de las conclusiones basadas en exclusiva en la evolución de una de ellas, o de las comparaciones entre distintas sociedades a partir del nivel o evolución de una sola de esas dimensiones.

\section{AGRADECIMIENTOS}

Este estudio ha contado con la ayuda de los proyectos de investigación HAR201454891-P y HAR-2016-75010-R. Agradezco mucho las observaciones de los evaluadores 
anónimos de Historia Agraria y de Ricardo Robledo, cuyas indicaciones impulsaron la reelaboración substancial de algunos aspectos y la incorporación de otros. Reconozco mi deuda con buen número de archiveros y archiveras por su auxilio irreemplazable, no siempre recordado, y con mis estudiantes por su paciencia ante mi curiosidad infinita por la desigualdad en cualquier tema que abordamos.

\section{REFERENCIAS}

Bradford Delong, J. (2016). Breve historia de la (des)igualdad. Project-Syndicate: The World's Opinion Page. https://www.project-syndicate.org/commentary/history-incomedistribution-by-j-bradford-delong-2016-07/spanish

Calatayud, S., Millán, J. \& Romeo, M. C. (Eds.) (2009). Estado y periferias en la España del siglo XIX: Nuevos enfoques. Valencia: Universitat de València.

Comisión de Estadística General del Reino (1860). Anuario Estadístico de España correspondiente a 1859 y 1860 . Madrid: Impr. Nacional.

DiRECCIÓN GENERAL DE LA PRODUCCIÓN AGRARIA (1974). Evaluación de recursos agrarios: Mapa de cultivos y aprovechamientos: Montilla (Córdoba). Madrid: Ministerio de Agricultura.

DireCCIÓn GENERAL DE LA PRODUCCIÓN AGRARIa (1977). Evaluacion de recursos agrarios: Mapa de cultivos y aprovechamientos: Puente Genil (Córdoba). Madrid: Ministerio de Agricultura.

EICHENGREEN B. (2016). Inequality. https://www.bis.org/events/conf160624/eichengreen_presentation.pdf

EsPINo, F. M. (2009). Todos los hombres de Isabel II: Diccionario biográfico de los protagonistas del reinado en Córdoba. Córdoba: Diputación Provincial de Córdoba.

GARCÍA GonZÁLEZ, F. (2016). Familia, desigualdad y reproducción social en la España rural, siglos XVI-XIX: Un balance historiográfico (2000-2014). En F. GARCÍA GonZÁLEZ, G. BÉAUR \& F. BOUdJAABA (Eds.), La historia rural en España y Francia (siglos XVI-XIX). Zaragoza: Prensas Universitarias de Zaragoza.

GARCÍA SANZ, A. (1994). La ganadería española entre 1750 y 1865: Los efectos de la reforma agraria liberal. Agricultura y Sociedad, (72). http://www.mapama.gob.es/ministerio/pags/Biblioteca/Revistas/pdf_ays\%2Fa072_03.pdf

GarRabou, R. \& Tello, E. (2004). Constructors de paisatges: Amos de masies, masovers i rabassaires al territori del Vallès (1716-1860). En fosep Fontana: Història i projecte social: Reconeixement a una trajectòria. Vol. 1. Barcelona: Crítica.

Garrabou, R., Planas, J., Saguer, E. \& Vicedo, E. (2014). Propiedad de la tierra y desigualdad social en el mundo rural catalán de mediados del siglo XIX. Historia Agraria, (63), 115-150. 
González de Molina, M., Infante, J., Soto, D. \& Herrera, A. (2011). Desigualdad y crecimiento agrario: Sobre las consecuencias sociales de la reforma agraria liberal en Andalucía, 1752-1904. XIII Congreso de Historia Agraria. Lleida, 12-14 de mayo. http://seha.info/congresos/2011/S2-Gonzalez\%20Molina\%20Manuell.pdf

González de Molina, M., Infante, J. \& Herrera, A. (2014). Cuestionando los relatos tradicionales: Desigualdad, cambio liberal y crecimiento agrario en el Sur peninsular (1752-1901). Historia Agraria, (63), 55-88.

Grupo de Estudios Agrarios (2002). Propiedad y explotación en la historia agraria de Andalucía: Una visión de conjunto. En M. GonZÁleZ DE Molina (Ed.), La historia de Andalucía a debate. II: El campo andaluz. Barcelona: Anthropos.

HorTAS, M. \& ONRUBIA, J. (2014). Renta personal de los municipios españoles y su distribución: Metodología de estimación a partir de microdatos tributarios. Estudios sobre la Economía Española, (12). http://documentos.fedea.net/pubs/eee/eee2014-12.pdf

INFANTE, J. (2012). Cuántos siglos de aceituna: El carácter de la expansión olivarera en el sur de España (1750-1900). Historia Agraria, (58), 39-72.

Instituto Geográfico Nacional (1872). Trabajos topográficos: Provincia de Córdoba: Comparación de las superficies dadas por el amillaramiento con las que resultan de los planos. Madrid: Instituto Geográfico Nacional.

Junta de Andalucía (2009). Encuesta de Cánones de Arrendamiento Rústico. http://www.mapama.gob.es/es/estadistica/temas/estadisticas-agrarias/C\%C3\%A1nones_Arrendamiento_2009_tcm7-156373.pdf

LóPEZ Estudillo, A. (2002). Transformacions agràries i retard econòmic: Andalusia 1850-1935. Estudis d'Història Agrària, (15). http://www.raco.cat/index.php/EHA/ article/view/99916

Llopis, E. (Ed.) (2004). El legado económico del Antiguo Régimen en España. Barcelona: Crítica.

López Estudillo, A. (2006). Los mercados de trabajo desde una perspectiva histórica: El trabajo asalariado agrario en la Andalucía Bética (la provincia de Córdoba). Revista Española de Estudios Agrosociales y Pesqueros, (211), 63-119. http://www.mapama. gob.es/ministerio/pags/Biblioteca/Revistas/pdf_REEAP\%2Fr211_3.pdf

López Estudillo, A. (2007). El arrendamiento de latifundios a partes de frutos: Contratos y gestión patrimonial del cabildo de la catedral de Córdoba (1700-1840). En R. ROBLEDo \& S. LóPEZ (Eds.), ¿Interés particular, bienestar público? Grandes patrimonios y reformas agrarias. Zaragoza: Prensas Universitarias de Zaragoza.

López Estudillo, A. (2008). Distribución social y efectos socioeconómicos de la fiscalidad rústica liberal: Aproximación a partir de la evolución de la presión fiscal agraria en el siglo XIX en la campiña de Córdoba. En R. VAllejo \& A. Furió (Coords.), Los tributos de la tierra: Fiscalidad y agricultura en España (siglos XII-XX).Valencia: Universitat de València. 
LóPEZ Estudillo, A. (2011). Evolución de la desigualdad agraria en los siglos XVIII-XX en Aguilar de la Frontera (Córdoba). XIII Congreso de Historia Agraria. Lleida, 1214 de mayo. http://seha.info/congresos/2011/S2-López\%20Estudillo\%20Antonio.pdf Martínez Alier. J. (1968). La estabilidad del latifundismo. Paris: Ruedo Ibérico.

MATA, R. (1987). Pequeña y gran propiedad agraria en la depresión del Guadalquivir:Aportación al estudio de la génesis y desarrollo de una estructura de propiedad agraria desigual. Madrid: Ministerio de Agricultura, Pesca y Alimentación.

Milanovic, B., Lindert, P. H. \& Williamson, J. G. (2011). Pre-Industrial Inequality. The Economic Fournal, 121 (551), 255-272.

NARANJo, J. (1998). Génesis del paisaje agrario olivarero-vitícola en la campiña de Córdoba: Aguilar y Moriles en el siglo XVIII. Córdoba: Diputación Provincial de Córdoba.

PiketTy, T. (2014). El capital en el siglo XXI. Madrid: Fondo de Cultura Económica.

SAAVEDRA, P. (2001). El campesinado en la España del Antiguo Régimen: Algunas consideraciones. En S. CASTILlO \& R. FERnÁNDEZ (Coords.), Campesinos, artesanos, trabajadores. Lleida: Milenio.

SánCHeZ Salazar, F. (1989). El olivo y su expansión en el Reino de Jaén durante el siglo XvIII. Boletín del Instituto de Estudios Giennenses, (138), 83-98.

Tello, E. \& BADiA-Miró, M. (2015). L'expansió de la frontera interior: Un model per explicar l'especialització vitícola catalana (1700-1939). En J. ColOMÉ, J. PlanAS \& F. VAlLs (Eds.), Vinyes, vins $i$ cooperativisme vitivinicola a Catalunya. Barcelona: Publicacions de l'Abadia de Montserrat.

Williamson, J. G. (2012a). Comercio y pobreza: Cuándo y cómo comenzó el atraso del Tercer Mundo. Barcelona: Crítica.

Williamson, J. G. (2012b). El desarrollo económico mundial en perspectiva histórica: Cinco siglos de revoluciones industriales, globalización y desigualdad. Zaragoza: Prensas Universitarias de Zaragoza.

WINDLER, C. (1997). Elites locales, señores, reformistas: Redes clientelares y Monarquia hacia finales del Antiguo Regimen. Sevilla: Universidad de Córdoba/Universidad de Sevilla.

Zambrana, J. F. (1987). Crisis y modernización del olivar español. Madrid: Ministerio de Agricultura, Pesca y Alimentación.

ZambranA, J. F. (2000). De grasa industrial a producto de mantel: Transformaciones y cambios en el sector oleícola español, 1830-1986. Revista de Historia Industrial, (18), 13-38. 